Check for updates

Cite this: Phys. Chem. Chem. Phys., 2018, 20, 13191

Received 20th February 2018 Accepted 12th April 2018

DOI: $10.1039 / c 8 c p 01159 a$

rsc.li/pccp

\section{Phenyl radical + propene: a prototypical reaction surface for aromatic-catalyzed 1,2-hydrogen- migration and subsequent resonance-stabilized radical formation $\dagger$}

\author{
Zachary J. Buras, (D) Te-Chun Chu, (D) Adeel Jamal, (D) Nathan W. Yee, (iD) \\ Joshua E. Middaugh (D) and William H. Green (D)*
}

\begin{abstract}
The $\mathrm{C}_{9} \mathrm{H}_{11}$ potential energy surface (PES) was experimentally and theoretically explored because it is a relatively simple, prototypical alkylaromatic radical system. Although the $\mathrm{C}_{9} \mathrm{H}_{11} \mathrm{PES}$ has already been extensively studied both experimentally (under single-collision and thermal conditions) and theoretically, new insights were made in this work by taking a new experimental approach: flash photolysis combined with time-resolved molecular beam mass spectrometry (MBMS) and visible laser absorbance. The $\mathrm{C}_{9} \mathrm{H}_{11}$ PES was experimentally accessed by photolytic generation of the phenyl radical and subsequent reaction with excess propene $\left(\mathrm{C}_{6} \mathrm{H}_{5}+\mathrm{C}_{3} \mathrm{H}_{6}\right)$. The overall kinetics of $\mathrm{C}_{6} \mathrm{H}_{5}+\mathrm{C}_{3} \mathrm{H}_{6}$ was measured using laser absorbance with high time-resolution from 300 to $700 \mathrm{~K}$ and was found to be in agreement with earlier measurements over a lower temperature range. Five major product channels of $\mathrm{C}_{6} \mathrm{H}_{5}+\mathrm{C}_{3} \mathrm{H}_{6}$ were observed with MBMS at 600 and $700 \mathrm{~K}$, four of which were expected: hydrogen $(\mathrm{H})$-abstraction (measured by the stable benzene, $\mathrm{C}_{6} \mathrm{H}_{6}$, product), methyl radical $\left(\mathrm{CH}_{3}\right)$-loss (styrene detected), $\mathrm{H}$-loss (phenylpropene isomers detected) and radical adduct stabilization. The fifth, unexpected product observed was the benzyl radical, which was rationalized by the inclusion of a previously unreported pathway on the $\mathrm{C}_{9} \mathrm{H}_{11}$ PES: aromatic-catalysed 1,2- $\mathrm{H}$-migration and subsequent resonance stabilized radical (RSR, benzyl radical in this case) formation. The current theoretical understanding of the $\mathrm{C}_{9} \mathrm{H}_{11}$ PES was supported (including the aromatic-catalyzed pathway) by quantitative comparisons between modelled and experimental MBMS results. At $700 \mathrm{~K}$, the branching to styrene $+\mathrm{CH}_{3}$ was 2-4 times greater than that of any other product channel, while benzyl radical $+\mathrm{C}_{2} \mathrm{H}_{4}$ from the aromaticcatalyzed pathway accounted for $\sim 10 \%$ of the branching. Single-collision conditions were also simulated on the updated PES to explain why previous crossed molecular beam experiments did not see evidence of the aromatic-catalyzed pathway. This experimentally validated knowledge of the $\mathrm{C}_{9} \mathrm{H}_{11} \mathrm{PES}$ was added to the database of the open-source Reaction Mechanism Generator (RMG), which was then used to generalize the findings on the $\mathrm{C}_{9} \mathrm{H}_{11}$ PES to a slightly more complicated alkylaromatic system.
\end{abstract}

\section{Introduction}

The addition of the phenyl radical, $\mathrm{C}_{6} \mathrm{H}_{5}$, to the unsaturated $\mathrm{C}=\mathrm{C}$ bond in propene, $\mathrm{C}_{3} \mathrm{H}_{6}$, produces two different propylbenzene radicals depending on the addition site, which are representative of a broader class of alkylaromatic radicals. As defined here, alkylaromatic radicals consist of an aromatic group, which can either be a single benzene ring or a polycyclic aromatic hydrocarbon (PAH) of arbitrary size, and at least one alkyl side chain of arbitrary length and branching on which the radical site resides. Alkylaromatic radicals can form either by "bottom-up" growth of smaller molecules, such as $\mathrm{C}_{6} \mathrm{H}_{5}+$ $\mathrm{C}_{3} \mathrm{H}_{6}$, ${ }^{1}$ or by "top-down" decomposition of larger molecules, such as in the combustion or pyrolysis of gasoline, diesel and 
jet fuels which contain significant amounts of closed-shell alkylaromatic compounds like propylbenzene. ${ }^{2}$ Once formed, the subsequent decomposition, growth or oxidation of alkylaromatic radicals can dictate the extent of $\mathrm{PAH}$ and soot formation, with potentially deleterious effects on climate $^{3}$ and human health. " Soot, or "coke", formation is also usually undesirable in industrial processes such as ethane steam cracking, ${ }^{5}$ where fouling of the reactor can necessitate costly shutdowns for cleaning. Alkylaromatic linkages and radicals are also important in the chemistry of heavy oils, coal, kerogen, lignin and many polymers. Therefore, understanding all of the ways in which alkylaromatic radicals can react is critical to a number of diverse applications including combustion, industrial cracking, organic geochemistry, and utilization of waste materials and biomass.

The two propylbenzene radicals directly formed by $\mathrm{C}_{6} \mathrm{H}_{5}+$ $\mathrm{C}_{3} \mathrm{H}_{6}$ have served as relatively simple surrogates for more complicated alkylaromatic radicals in many top-down experimental and theoretical studies of propylbenzene oxidation and pyrolysis, recently summarized by Yuan et al., ${ }^{2}$ and in nine bottom-up studies utilizing $\mathrm{C}_{6} \mathrm{H}_{5}+\mathrm{C}_{3} \mathrm{H}_{6}$ (including this work) summarized in Table 1. From this large body of work on the $\mathrm{C}_{9} \mathrm{H}_{11}$ potential energy surface (PES) a consensus has emerged (with some caveats discussed below) regarding the major expected reaction pathways of the $\mathrm{C}_{6} \mathrm{H}_{5}+\mathrm{C}_{3} \mathrm{H}_{6}$ system, shown in Scheme 1. $\mathrm{C}_{6} \mathrm{H}_{5}$ mostly reacts with $\mathrm{C}_{3} \mathrm{H}_{6}$ by addition to the terminal and central $\mathrm{C}=\mathrm{C}$ sites, and by hydrogen, $\mathrm{H}$, abstraction from the allylic carbon in $\mathrm{C}_{3} \mathrm{H}_{6}$. The two propylbenzene radicals formed by addition can easily interconvert via a 1,2phenyl-migration, and are usually assumed to be equilibrated at combustion-relevant temperatures. The central-addition product will mostly $\beta$-scission a methyl radical, $\mathrm{CH}_{3}$, to form styrene, whereas the terminal-addition product will $\beta$-scission an $\mathrm{H}$ on one of the two neighbouring carbons to form 3- or 1phenylpropene. Alternatively, if the radical site on the terminal addition product can shift to the end of the alkyl chain via a 1,2$\mathrm{H}$-migration, the resulting alkylaromatic radical can either $\beta$ scission an ethene, $\mathrm{C}_{2} \mathrm{H}_{4}$, to form a benzyl radical or it can undergo a secondary ring-closure to form a five-membered ring. Subsequent $\beta$-scission of an $\mathrm{H}$ from the bicyclic radical forms indane, which can form indene following loss of two more $\mathrm{H}$ atoms. Indene is a precursor to $\mathrm{PAH}$ and soot, and it is mostly because of this potential route to indene that $\mathrm{C}_{6} \mathrm{H}_{5}+$ $\mathrm{C}_{3} \mathrm{H}_{6}$ has been of such interest. ${ }^{1}$ However, the 1,2-H-migration that enables indane formation has a barrier at least 6 kcal $\mathrm{mol}^{-1}$ higher than the various $\beta$-scissions mentioned above, rendering that pathway uncompetitive, even under combustion conditions. ${ }^{11}$ The lack of indane formation from $\mathrm{C}_{6} \mathrm{H}_{5}+\mathrm{C}_{3} \mathrm{H}_{6}$ and the dominance of styrene and phenylpropene isomers as products is supported both by calculations of the product branching $^{9,11}$ and by experiments conducted under singlecollision $^{8,9,12}$ and thermal environments. ${ }^{10}$

The single-collision experiments, conducted in crossed molecular beam (CMB) apparatuses with Quadrupole Mass Spectrometry (QMS) detection, ruled out significant indane formation at collision energies, $E_{\text {col }}$, of $\sim 10 \mathrm{kcal} \mathrm{mol}^{-1}$ (ref. 9)

Table 1 Summary of the literature on the phenyl radical + propene system

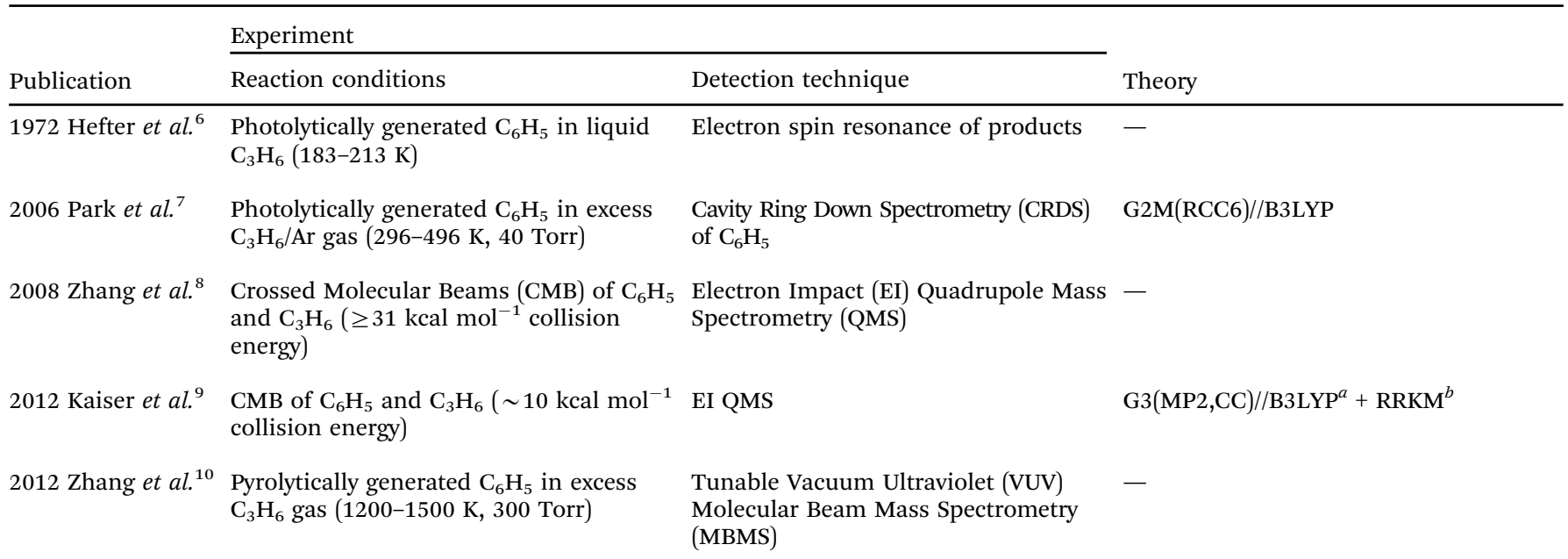

2012 Kislov et al. ${ }^{11}$

2013 Albert et al. ${ }^{12}$ CMB of $\mathrm{C}_{6} \mathrm{H}_{5}+\mathrm{C}_{3} \mathrm{H} 6\left(\geq 20 \mathrm{kcal} \mathrm{mol}^{-1} \quad\right.$ VUV QMS collision energy)

2014 Wang et al. ${ }^{13}$

This work

Photolytically generated $\mathrm{C}_{6} \mathrm{H}_{5}$ in excess $\mathrm{C}_{3} \mathrm{H}_{6} / \mathrm{He}$ gas (295-707 K, 10-50 Torr)
$\mathrm{G} 3(\mathrm{MP} 2, \mathrm{CC}) / / \mathrm{B}^{2} \mathrm{LYP}^{a}+\mathrm{RRKM}^{b} / \mathrm{ME}^{c} / \mathrm{TST}^{d}$

$-$

CBS-QB3 $+\mathrm{TST}^{d}$

Multiple-pass laser absorbance of $\mathrm{C}_{6} \mathrm{H}_{5}$, $\mathrm{C}_{3} \mathrm{H}_{5}$ and $\mathrm{C}_{7} \mathrm{H}_{7}+$ VUV Time-of-Flight (TOF) MBMS
$\mathrm{G} 3(\mathrm{MP} 2, \mathrm{CC}) / / \mathrm{B}^{2} \mathrm{LYP}^{a}+\mathrm{RRKM}^{b} / \mathrm{ME}^{c} / \mathrm{TST}^{d}$

\footnotetext{
${ }^{a}$ Same level of theory as that used in this work, which is described in the Theoretical section. ${ }^{b}$ RRKM $=$ Rice-Ramsperger-Kassel-Marcus theory for $k(E) .{ }^{c} \mathrm{ME}=$ Master equation model of $T, P$-dependent kinetics. ${ }^{d}$ TST = transition state theory for high- $P, T$-dependent kinetics.
} 


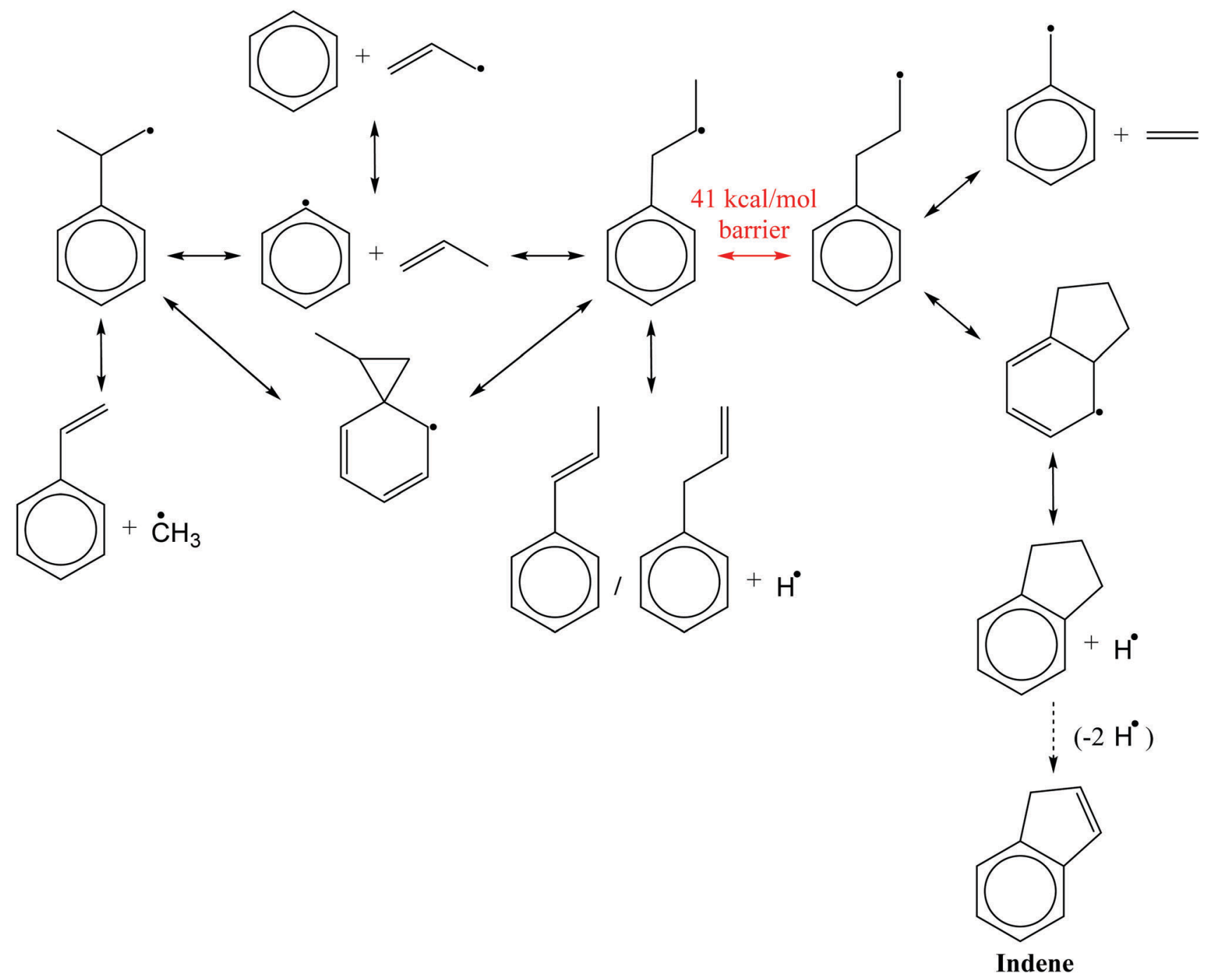

Scheme 1 Major expected reaction pathways of phenyl radical + propene.

and $\sim 30 \mathrm{kcal} \mathrm{mol}^{-1}$ (ref. 8) based on both the measured exoergicity of the $\mathrm{H}$-loss channel and from experiments with deuterated $\mathrm{C}_{3} \mathrm{H}_{6}$. The thermal experiment, conducted in a fast pyrolysis reactor maintained at $1200-1500 \mathrm{~K}$ in 300 Torr of $\mathrm{C}_{3} \mathrm{H}_{6}$, ruled out indane formation based on the measured photoionization efficiency (PIE) curves of the product(s) at a mass-to-charge ratio, $\mathrm{m} / z$, of $118 \mathrm{amu}$, corresponding to the mass of the various $\mathrm{H}$-loss products with the molecular formula $\mathrm{C}_{9} \mathrm{H}_{10}$.

Although there is qualitative agreement in the literature regarding what the major products of $\mathrm{C}_{6} \mathrm{H}_{5}+\mathrm{C}_{3} \mathrm{H}_{6}$ should (styrene and phenylpropene isomers) and should not (indane) be, quantitatively there are three discrepancies. First, the extent of $\mathrm{H}$-abstraction is predicted to be significant, increasing from $\sim 10 \%$ of the product branching at $300 \mathrm{~K}$ to $\sim 80 \%$ at $3000 \mathrm{~K},{ }^{11}$ but this has never been quantified experimentally. Of the six previous experimental studies listed in Table 1 , only the photolysis experiments of Hefter et al. in liquid $\mathrm{C}_{3} \mathrm{H}_{6}$ reported measurable products of $\mathrm{H}$-abstraction: benzene, $\mathrm{C}_{6} \mathrm{H}_{6}$, and allyl radical, the most thermodynamically stable of the $\mathrm{C}_{3} \mathrm{H}_{5}$ isomers. ${ }^{6}$
In that work, $\mathrm{C}_{6} \mathrm{H}_{5}$ was found to prefer radical addition to the terminal $\mathrm{C}=\mathrm{C}$ carbon in propene over the other two major entrance reactions (Scheme 1), consistent with the low temperatures used (182-213 K). Of the two remaining experiments conducted in a thermal reactor, the fast pyrolysis experiment of Zhang et al. was done under aggressive conditions that would encourage many side, secondary, tertiary and higher reactions, ${ }^{10}$ making it impossible to extract quantitative information about the underlying chemistry without a detailed kinetic mechanism. The Cavity Ring Down Spectrometry (CRDS) experiments of Park et al. were conducted under more controlled conditions, and the probe laser wavelength used, $504.8 \mathrm{~nm}$, was tuned to a known absorbance feature of $\mathrm{C}_{6} \mathrm{H}_{5},{ }^{14}$ where few other radicals absorb, enabling selective detection of $\mathrm{C}_{6} \mathrm{H}_{5} .{ }^{7}$ While convenient for accurate quantification of overall consumption rates, selective detection of a photolytically generated radical reactant $\left(\mathrm{C}_{6} \mathrm{H}_{5}\right.$ in this case) leaves the experimentalist blind to subsequent product formation, which was the case in Park et $a l^{7}$ Finally, all three of the $\mathrm{CMB}$ experiments with QMS detection were unable to detect either $\mathrm{C}_{3} \mathrm{H}_{5}$ or $\mathrm{C}_{6} \mathrm{H}_{6}$, likely due to lower sensitivity for light 
species and overlap with the large ${ }^{13} \mathrm{C}$ peak of scattered $\mathrm{C}_{6} \mathrm{H}_{5},{ }^{12}$ respectively.

The second quantitative discrepancy is the extent of $\mathrm{CH}_{3}$-loss relative to $\mathrm{H}$-loss. Kaiser et al. computed relative product yields under single-collision conditions by combining G3(MP2,CC)//B3LYP calculations of the $\mathrm{C}_{9} \mathrm{H}_{11}$ PES with microcanonical Rice-Ramsperger-Kassel-Marcus (RRKM) theory for energy-dependent rate coefficients, $k(E)$, and then applying the steady-state approximation to the set of differential equations describing the reaction network. ${ }^{9}$ This calculation does not include the contribution of $\mathrm{H}$-abstraction because as noted above it was not possible to observe the products of $\mathrm{H}$-abstraction in the $\mathrm{CMB}$ experiments. The single-collision product calculations of Kaiser et al. were quantitatively consistent with CMB experiments reported in that same work at $E_{\mathrm{col}} \approx 10 \mathrm{kcal} \mathrm{mol}^{-1}$, where yields of $\mathrm{CH}_{3^{-}}$and $\mathrm{H}$-loss products were measured as $\sim 70 \%$ and $\sim 30 \%$, respectively. At higher $E_{\text {col }}$ it was predicted that the yield of $\mathrm{CH}_{3}$-loss would drop steadily to $\sim 20 \%$ at $\sim 45 \mathrm{kcal} \mathrm{mol}^{-1}$ to be replaced by various H-loss products (mostly 3-phenylpropene). This prediction was also consistent with earlier CMB experiments at $E_{\text {col }}>30 \mathrm{kcal} \mathrm{mol}^{-1}$, where only H-loss products were observed, and the $\mathrm{CH}_{3}$-loss yield was approximated as $<10 \%$ due to the detection limit. ${ }^{8}$ However, Albert et al. measured a much higher relative product yield of $\mathrm{CH}_{3}-$ to $\mathrm{H}$-loss at intermediate $E_{\text {col' }}$ 's of $\sim 20$ and $25 \mathrm{kcal} \mathrm{mol}^{-1}$ than expected based on the calculations of Kaiser et al:: $\sim 10: 1$ and $\sim 3: 1$, respectively. ${ }^{12}$ One proposed explanation for the experimental discrepancy between Albert et al. and Kaiser et al. is that the latter used $80 \mathrm{eV}$ electron impact ionization, necessitating the deconvolution of fragments, whereas the former used $9.9 \mathrm{eV}$ "soft" vacuum ultraviolet (VUV) photoionization (PI). Furthermore, the G3(MP2,CC)//B3LYP $\mathrm{C}_{9} \mathrm{H}_{11}$ PES first reported by Kaiser et al. was later combined with RRKM theory to solve the master equation (ME) describing temperature- and pressure-dependent kinetics under thermal conditions. ${ }^{11}$ These thermal calculations predict similar yields of $\mathrm{CH}_{3}$ and $\mathrm{H}$-loss products from 1200 to $1500 \mathrm{~K}$ and at 300 Torr, whereas Zhang et al. measured $\sim 5 \times$ more styrene from $\mathrm{CH}_{3}$-loss than the sum of all $\mathrm{H}$-loss products under the same conditions. As mentioned earlier, however, this discrepancy could be due to secondary chemistry occurring during the pyrolysis.

Finally, there is disagreement regarding the identity of the dominant $\mathrm{H}$-loss isomer. While there is wide agreement that styrene is the dominant $\mathrm{CH}_{3}$-loss product, there are conflicting reports in the literature as to whether 3-phenylpropene or 1-phenylpropene dominates $\mathrm{H}$-loss. Both the single-collision and thermal calculations of Kaiser et al. ${ }^{9}$ and Kislov et al. ${ }^{11}$ respectively, predict that 3-phenylpropene will have the highest yield of any $\mathrm{H}$-loss product by far over all conditions considered. This is in nominal agreement with the PIE curves measured at $m / z=118$ amu by Zhang et al., which could be fit by assuming almost 100\% 3-phenylpropene, but given the number of potential $118 \mathrm{amu}$ isomers (indane, both cis- and trans-1-phenylpropene, 2-phenylpropene and 3-phenylpropene) this fit is best considered as just one possible solution. ${ }^{10}$ In contrast, the earlier CMB experiments of Zhang et al. identified 1-phenylpropene as the dominant $\mathrm{H}$-loss isomer at $E_{\mathrm{col}} \approx 45 \mathrm{kcal} \mathrm{mol}^{-1}$ based on experiments with deuterated isotopologues of $\mathrm{C}_{3} \mathrm{H}_{6}{ }^{8}$ Albert et al. also tentatively assigned the $\mathrm{H}$-loss product observed in $\sim 20-25 \mathrm{kcal} \mathrm{mol}^{-1} \mathrm{CMB}$ experiments to 1-phenylpropene, based on analogy to the products observed from $\mathrm{C}_{6} \mathrm{H}_{5}+$ 2-butene, $2-\mathrm{C}_{4} \mathrm{H}_{8}$, in the same work. ${ }^{12}$

This work aims to alleviate the first two of the three discrepancies summarized above (extent of $\mathrm{H}$-abstraction and the extent of $\mathrm{CH}_{3}$ - to $\mathrm{H}$-loss) by applying a different detection technique to the problem: time-resolved molecular beam MS (MBMS) with VUV PI. The reaction conditions used here are most similar to those in the work of Park et al. ${ }^{7}$ (photolytically generated $\mathrm{C}_{6} \mathrm{H}_{5}$ in a thermal environment), but the use of timeresolved MBMS for detection allows for quantification of all products as they are formed, including $\mathrm{C}_{6} \mathrm{H}_{6}$ from $\mathrm{H}$-abstraction. Additionally, unlike the fast pyrolysis experiments of Zhang, which also used MBMS under thermal conditions, the primary products of $\mathrm{C}_{6} \mathrm{H}_{5}+\mathrm{C}_{3} \mathrm{H}_{6}$ can be easily distinguished from later generation products based on their faster appearance, enabling more conclusive quantification of $\mathrm{CH}_{3}$ - to $\mathrm{H}$-loss as a function of temperature and pressure. The experimental apparatus used in this work is also equipped to perform multiple-pass laser absorbance measurements, allowing for precise quantification of the overall $\mathrm{C}_{6} \mathrm{H}_{5}$ consumption rate, which is compared to the CRDS measurements of Park et al. ${ }^{7}$ Finally, benzyl radical was observed as an unexpected primary product of $\mathrm{C}_{6} \mathrm{H}_{5}+\mathrm{C}_{3} \mathrm{H}_{6}$. This finding was rationalized by the inclusion of a new "aromatic-catalyzed" 1,2-hydrogen-migration pathway on the $\mathrm{C}_{9} \mathrm{H}_{11}$ PES. All experimental measurements were quantitatively compared to the predictions of the Reaction Mechanism Generator (RMG), which was then used to predict the products of a slightly more complicated alkylaromatic system, 1-naphthyl + 2-butene, in order to demonstrate the general applicability of the insights made into the $\mathrm{C}_{6} \mathrm{H}_{5}+\mathrm{C}_{3} \mathrm{H}_{6}$ system.

\section{Experimental}

A previous version of the experimental apparatus has been described before, ${ }^{15,16}$ and the latest version will be described in detail in a forthcoming publication. ${ }^{17} \mathrm{~A}$ brief description is provided here, with an emphasis on two major changes made to the apparatus since the last publication.

The apparatus consists of a custom quartz flow-reactor housed in a high vacuum chamber equipped with a time-offlight MS (TOF-MS). Switching from a stainless steel reactor with $\sim 6 \mathrm{~cm}$ inner diameter to a more compact quartz reactor described below was the first major change to the apparatus. The new reactor is $1 \mathrm{~m}$ long with a $16 \mathrm{~mm}$ inner diameter ( $2.5 \mathrm{~mm}$ wall thickness) in the central $0.4 \mathrm{~m}$ and a $36 \mathrm{~mm}$ inner diameter ( $2 \mathrm{~mm}$ wall thickness) everywhere else. Gases are mixed upstream and pumped through the reactor by a Roots blower. Pressure is controlled in the reactor by throttling a butterfly valve at the exit. The contents of the flow reactor are coaxially flashed by a collimated $266 \mathrm{~nm}$ laser beam (fourth harmonic frequency of an Nd:YAG laser) at a set repetition rate 
(usually $1 \mathrm{~Hz}$ ). The total gas flow through the reactor is set such that one flash per refresh (FPR) conditions are maintained. The photolysis beam is expanded by a set of telescoping lenses and clipped by an adjustable iris to the same diameter as the narrow section of the reactor $(16 \mathrm{~mm})$. This approach to setting the photolysis beam diameter (expand and then clip) is intended to reduce radial inhomogeneities at the edges of the beam. A "funnel-shaped" pinhole, similar to that used by Wyatt et al., ${ }^{18}$ is drilled in the center of the reactor with a $275 \mu \mathrm{m}$ diameter at the narrowest point. A small portion of the reactor contents are sampled through the pinhole, and the center of the resulting gas expansion is skimmed by a Beam Dynamics skimmer (Model 16.3, $1.0 \mathrm{~mm}$ orifice diameter), forming a molecular beam. After traversing $\sim 50 \mathrm{~mm}$, the molecular beam intersects with a focused $118 \mathrm{~nm}(10.5 \mathrm{eV})$ PI laser beam (ninth harmonic frequency of an Nd:YAG laser). Cations formed in the ionization region are accelerated, focused, and guided to the detector of the Kore TOF-MS (ETP electron multiplier, model AF824) by a set of ion optics.

The second major change to the apparatus was to separate the residual $355 \mathrm{~nm}$ radiation from the desired $118 \mathrm{~nm}$ PI radiation by an off-axis $\mathrm{MgF}_{2}$ lens. Once the two beams have been dispersed, only the $118 \mathrm{~nm}$ beam is allowed to enter the ionization region by passing through a pinhole, while the $355 \mathrm{~nm}$ beam is blocked. Preventing the excess $355 \mathrm{~nm}$ radiation from reaching the ionization region was necessary to avoid excessive fragmentation and multiphoton ionization. The approach to separating the two wavelengths described here (essentially using the $\mathrm{MgF}_{2}$ lens as a prism) was adapted from Tonokura et al. ${ }^{19}$

As mentioned earlier, the apparatus is also equipped to do multiple-pass UV-visible laser absorbance, and single-pass IR absorbance of the iodine, I, atom. Details of this portion of the apparatus have been given numerous times before, ${ }^{20,21}$ and will not be repeated here. Although the quartz reactor is much narrower than the previous reactor, it was designed to accommodate the multiple-pass Herriott cell, hence the custom "bow-tie" geometry of the reactor. ${ }^{17}$

Previously, with the larger diameter, stainless steel reactor, the radicals formed by photolysis were concentrated in a relatively small central section of the reactor $(\sim 1.3 \mathrm{~cm}$ diameter), and would diffuse outwards radially on a timescale commensurate with the kinetics of interest $(\sim 10 \mathrm{~ms}$ at $\sim 10$ Torr). With the new reactor, by adjusting the photolysis beam diameter to match the inner diameter of the central $0.4 \mathrm{~m}$, radial diffusion out of the MBMS sampling region can be eliminated as a loss process. The longest kinetic time-scales that can be measured with MBMS is now set by the time it takes for the gas to flow through the narrow, central section ( $\sim 50 \mathrm{~ms}$ for a $1 \mathrm{~Hz}$ experiment).

Switching the reactor material from stainless steel to quartz was also intended to reduce wall reactions that were most clearly manifested by fast hydrogenation of $\mathrm{C}_{6} \mathrm{H}_{5}$ to $\mathrm{C}_{6} \mathrm{H}_{6}$. However, even after treating the quartz reactor with boric acid following the procedure of Krasnoperov et al., ${ }^{22}$ this manifestation of wall reactions was never entirely eliminated (Fig. S9, S18, S29 and S33, ESI $\dagger$ ). Nonetheless, control experiments described in the Results and discussion section demonstrate that wall reactions do not noticeably affect the main observations and conclusions made in this work.

The reactor is heated by nichrome ribbon wire in two temperature-controlled zones. There is a short, $5 \mathrm{~cm}$ "pre-heat zone" just upstream of where the Herriott cell and the photolysis laser overlap. The gas entering this zone is still at room temperature and is quickly heated to the desired temperature. The following "reaction zone" encompasses almost the entire remaining length of the reactor and maintains near isothermal conditions at the desired temperature. The thermocouples used to control the power supplied to each heater are located inside the reactor at the exit of each zone (out of the path of the photolysis laser). Axial temperature profiles were measured under different experimental conditions and are reported in the Results and discussion section. For the absorbance experiments, the temperature reported is the average $T(z)$ over the central $0.5 \mathrm{~m}$, where the Herriott cell and photolysis laser overlap. For the MBMS experiments, the temperature reported is the average in the $0.2 \mathrm{~m}$ narrow section on the inlet side of the sampling pinhole. Uncertainties reported are two standard deviations over the same axial range.

Both iodobenzene $\left(\mathrm{C}_{6} \mathrm{H}_{5} \mathrm{I}\right.$; Sigma-Aldrich, 98\%) and nitrosobenzene $\left(\mathrm{C}_{6} \mathrm{H}_{5} \mathrm{NO}\right.$; Sigma-Aldrich, $\left.\geq 97 \%\right)$ were used as photolytic precursors of $\mathrm{C}_{6} \mathrm{H}_{5}$ because both are known to almost entirely photodissociate to $\mathrm{C}_{6} \mathrm{H}_{5}+\mathrm{I} / \mathrm{NO}$ at $266 \mathrm{~nm} .^{23,24}$ Iodobenzene was purged of oxygen by successive freeze-pump-thaw cycles, while nitrosobenzene, a powder at room temperature, was simply degassed. Both precursors were placed in air-tight bubblers and introduced into the reactor by flowing a controlled amount of helium through/over them. Because of the strong reactivity of $\mathrm{C}_{6} \mathrm{H}_{5}$ towards $\mathrm{O}_{2}{ }^{14}$ even $\sim 100 \mathrm{ppm}$ of residual air in the reactor could have a measurable impact on the experiments. The clearest indicators of $\mathrm{O}_{2}$ present somewhere in the reactor or associated gas lines are a strong visible absorbance signal from the phenylperoxy radical, $\mathrm{C}_{6} \mathrm{H}_{5} \mathrm{OO},{ }^{25}$ and a product at $m / z=94$ amu (likely phenol, $\mathrm{C}_{6} \mathrm{H}_{5} \mathrm{OH}$, also seen by Zhang et al. ${ }^{10}$ ) in the MS following photolytic $\mathrm{C}_{6} \mathrm{H}_{5}$ generation. When $\mathrm{C}_{6} \mathrm{H}_{5} \mathrm{I}$ was used as the precursor, it was possible to eliminate all signs of $\mathrm{O}_{2}$ from the experiment. With $\mathrm{C}_{6} \mathrm{H}_{5} \mathrm{NO}$, however, there was always some residual $\mathrm{O}_{2}$ in the precursor, manifested by both $\mathrm{C}_{6} \mathrm{H}_{5} \mathrm{OO}$ absorbance and $\mathrm{C}_{6} \mathrm{H}_{5} \mathrm{OH}$ MS signal. $\mathrm{C}_{6} \mathrm{H}_{5} \mathrm{I}$ can also be used up to $900 \mathrm{~K}$ before thermal decomposition on the residence time scale of this experiment $(1 \mathrm{~s})$ becomes important, ${ }^{26}$ whereas for $\mathrm{C}_{6} \mathrm{H}_{5} \mathrm{NO}$ the limit is only $700 \mathrm{~K}^{24}$ The I atom from $\mathrm{C}_{6} \mathrm{H}_{5} \mathrm{I}$ photolysis can also be quantified by IR absorbance, providing an estimate of the initial $\mathrm{C}_{6} \mathrm{H}_{5}$ concentration. For all of these reasons, $\mathrm{C}_{6} \mathrm{H}_{5} \mathrm{I}$ was the precursor of choice for almost all of the experiments reported here.

Helium, He, was used as the bath gas in all experiments reported here and was purchased from Airgas (UHP grade, 99.999\%). $\mathrm{C}_{3} \mathrm{H}_{6}$ was also purchased from Airgas (CP grade, 99\%) and used without further purification.

\section{Theoretical}

Much of the $\mathrm{C}_{9} \mathrm{H}_{11}$ PES has already been explored both by Park et al. using $\mathrm{G} 2 \mathrm{M}(\mathrm{RCC} 6) / / \mathrm{B}^{2} \mathrm{LYP}^{7}$ and by Kislov et al. using 
G3(MP2,CC)//B3LYP. ${ }^{11}$ Wang et al. reported CBS-QB3 calculations on a portion of the PES, focused on the 1,2-phenyl-migration connecting the terminal and central addition products. ${ }^{13}$ This work took the $\mathrm{C}_{9} \mathrm{H}_{11}$ PES calculated by Kislov et al., and added on one new $\mathrm{C}_{9} \mathrm{H}_{11}$ isomer, three new transition states (TSs) and one new bimolecular product channel (benzyl radical, $\mathrm{C}_{7} \mathrm{H}_{7}$, + ethene, $\mathrm{C}_{2} \mathrm{H}_{4}$ ) that together comprise the newly discovered aromaticcatalyzed 1,2-H-migration and subsequent resonance stabilized radical (RSR) formation pathway. For consistency, the same level of theory was used. Briefly, geometries and frequencies of the new minima and saddle points were optimized using B3LYP/ 6-311G(d,p). Starting from the optimized geometries, relaxed potential energy scans were performed (also using B3LYP/ $6-311 \mathrm{G}(\mathrm{d}, \mathrm{p}))$ as a function of the dihedral angle in $10^{\circ}$ increments around all $\mathrm{C}-\mathrm{C}$ and nascent $\mathrm{C}-\mathrm{C}$ bonds that are likely to undergo internal rotation for all stationary points on the $\mathrm{C}_{9} \mathrm{H}_{11}$ PES. In some cases the scan revealed that the starting geometry was not the conformational minimum and the geometry was re-optimized accordingly. The $0 \mathrm{~K}$ electronic energies of the optimized geometries were refined by using a simplified version of the composite G3(MP2,CC) method:

$$
\begin{aligned}
E_{0}[\mathrm{G} 3(\mathrm{MP} 2, \mathrm{CC})]= & E[\mathrm{RCCSD}(\mathrm{T}) / 6-311 \mathrm{G}(\mathrm{d}, \mathrm{p})]+(E[\mathrm{MP} 2 / \mathrm{G} 3 \text { large }] \\
& -E[\mathrm{MP} 2 / 6-311 \mathrm{G}(\mathrm{d}, \mathrm{p})])+E(\mathrm{ZPE})
\end{aligned}
$$

The first term on the right-hand side is the ground state electronic energy calculated with a high level of theory (spinrestricted coupled cluster) and a small basis set (6-311G(d,p)). The second term is an estimation of the error introduced by using a small basis set instead of a larger one (G3large, in this case). The last term is the zero point energy (ZPE) correction, calculated based on the B3LYP frequencies scaled by a recommended factor of $0.967 .{ }^{27}$ The G3(MP2,CC)//B3LYP method has been applied to many aromatic-containing PESs because it offers a good compromise between accuracy and computational cost. ${ }^{1,28}$ Gaussian03 ${ }^{29}$ was used for all B3LYP calculations, and Molpro $^{30}$ was used for all coupled cluster calculations. The geometries, frequencies, rotational constants, dihedral angle scans and electronic energies for all stationary points on the $\mathrm{C}_{9} \mathrm{H}_{11}$ PES are reported in the ESI. $\dagger$

Both high-pressure $(P)$ and $P$-dependent thermal rate coefficients, $k(T)$ and $k(T, P)$, were calculated on the G3(MP2,CC)//B3LYP $\mathrm{C}_{9} \mathrm{H}_{11}$ PES using Cantherm, an open-source software included with RMG. ${ }^{31}$ $k(T)$ 's for every elementary chemical reaction were calculated by canonical transition state theory (TST) using the rigid-rotor harmonic oscillator (RRHO) approximation with low-energy $\left(<10 \mathrm{kcal} \mathrm{mol}^{-1}\right.$ barrier) internal rotations modelled as onedimensional hindered rotors (1D-HR). Tunnelling was modelled using the $1 \mathrm{D}$-asymmetric Eckart correction. ${ }^{32}$ Phenomenological $k(T, P)$ 's were fit by applying RRKM/ME under the modified strong collision (MSC) approximation (RRHO and 1D-HR approximations also used in calculating densities of states). ${ }^{33}$ For the two barrierless exit channels found by Kislov et al., the high- $P$ variational TST $k(T)$ 's calculated in that work were input to Cantherm and converted into $k(E)$ 's for solution of the ME by inverse Laplace transform. ${ }^{33}$ Lennard-Jones and collisional energy-transfer (CET) parameters were taken from Mebel et al. for an argon bath gas, ${ }^{1}$ and scaled down for a helium bath gas using the calculations of Jasper et al. ${ }^{34}$

The same custom scripts used in Kaiser et al. ${ }^{9}$ for simulating single-collision experiments on the $\mathrm{C}_{9} \mathrm{H}_{11}$ PES were also used here on the expanded PES. $k(E)$ 's were calculated using RRKM at a fixed $E$ corresponding to $E_{\text {col }}$. Using the calculated $k(E)$ values, a system of ordinary differential equations (ODEs) was constructed that describes the connectivity of the PES. The initial composition was set to either $100 \%$ of the terminal or $100 \%$ of the central addition adduct. The ODEs were solved under the steady-state approximation in order to determine predicted product branching as a function of $E_{\text {col }}$ for comparison to $\mathrm{CMB}$ experiments. The product branching for the two different initial adducts were very similar, and the total product branching was estimated by summing the two sets of calculations weighted by the expected thermal branching between terminal and central addition. The temperature used to evaluate the thermal branching was calculated as $2 / 3 \times E_{\mathrm{col}} / R$, or the temperature at which the average kinetic energy in a Boltzmann distribution is $E_{\text {col}}$.

Finally, all elementary reactions on the $\mathrm{C}_{9} \mathrm{H}_{11}$ PES were added as training reactions to the RMG database. ${ }^{31}$ Scheme 2 gives an example of one of the training reactions added in this work and its position in the larger RMG database hierarchy. High- $P$ kinetic data are provided with each training reaction and in this case the TST calculated $k(T)$ 's were used. The kinetic portion of

Reaction Family: intra_H_Migration

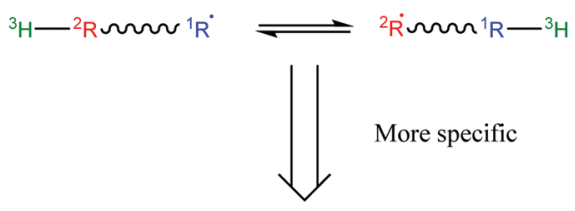

Reaction Template

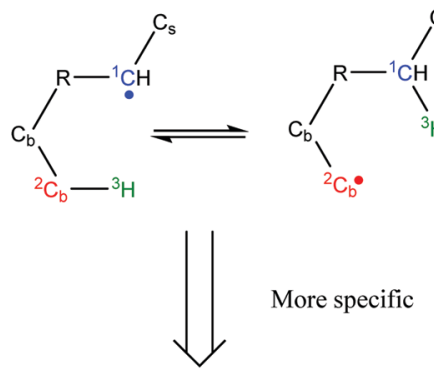

Training Reaction: i1 $\Leftrightarrow$ i12 calculated using G3(MP2,CC)//B3LYP + TST

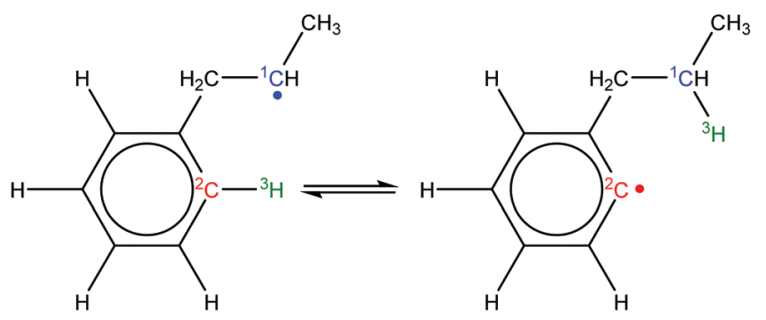

Scheme 2 Example of an RMG training reaction and its position in the hierarchy of the RMG database. 
the RMG database is currently divided into $\sim 50$ reaction families common to gas-phase combustion chemistry, such as intramolecular H-migration (abbreviated as intra_H_migration). Each family uses reaction templates to describe the critical details for a given reaction. In the example given, the reaction template specifies a 1-4-H-migration from a carbon in a benzene ring (identified by the atom label " $\mathrm{Cb}$ ") to a secondary carbon radical. The template can also provide information about atoms not directly involved in the reaction. For example, one of the atoms between the two reacting ends is another $\mathrm{Cb}$, and one of the atoms bonded to the radical carbon is a $\mathrm{Cs}$ (a carbon with only single bonds, i.e., an $\mathrm{sp}^{3}$ carbon). Such details can have large impacts on the real kinetics, so it is critical for RMG to be aware of these details to make good estimates for reactions with unknown kinetics. Training reactions are the most specific representations of a reaction in the RMG database. When RMG proposes a reaction with unknown kinetics during automatic mechanism generation, it will match the new reaction to similar training reactions based on their similar reaction templates, utilizing the kinetic parameters of the training reactions to estimate parameters for the new reaction. For example, this work is primarily concerned with $\mathrm{C}_{6} \mathrm{H}_{5}+\mathrm{C}_{3} \mathrm{H}_{6}$, but any arbitrary alkylaromatic radical system, such as 1-naphthyl +2 -butene, $1-\mathrm{C}_{10} \mathrm{H}_{7}+2-\mathrm{C}_{4} \mathrm{H}_{8}$, will undergo many of the same reactions with similar kinetics and heats of reaction. By training the RMG database on reliable kinetics for the $\mathrm{C}_{9} \mathrm{H}_{11}$ system, the knowledge gleaned from that specific system will automatically be applied to every analogous alkylaromatic system, including $1-\mathrm{C}_{10} \mathrm{H}_{7}+2-\mathrm{C}_{4} \mathrm{H}_{8}$. This analogy is explored in more detail in Section 4.6.

\section{Results and discussion}

\subsection{Calculated energetics and kinetics of $\mathrm{C}_{9} \mathrm{H}_{11}$ PES}

Fig. 3 shows a reduced version of Kislov et al.'s G3(MP2,CC)// B3LYP $\mathrm{C}_{9} \mathrm{H}_{11}$ PES $^{11}$ appended with the aromatic-catalyzed 1,2$\mathrm{H}$-migration and subsequent RSR formation pathway calculated in this work. For clarity, only the kinetically important features of the PES are shown, and the same intermediate and product names are used as in the previous work (e.g., i1 for intermediate $\mathbf{1}$ and $\mathbf{p} \mathbf{1}$ for product $\mathbf{1}$, which is styrene). The major expected pathways of $\mathrm{C}_{6} \mathrm{H}_{5}+\mathrm{C}_{3} \mathrm{H}_{6}$ forming styrene (p1), benzene $\left(\mathrm{C}_{6} \mathrm{H}_{6}\right)$ and phenylpropene isomers (p2-p4) have already been discussed in the Introduction and will not be repeated here.

The relatively high-energy $\left(\sim 40 \mathrm{kcal} \mathrm{mol}^{-1}\right)$ direct $1,2-\mathrm{H}-$ shift from i1 to $\mathbf{i} 4$ is highlighted in red, and the lower-energy $\left(\sim 30 \mathrm{kcal} \mathrm{mol}^{-1}\right)$ aromatic-catalyzed 1,2-H-shift is highlighted in green. Once $\mathbf{i 4}$ is formed, it can produce indane (p5) in two steps, as discussed in the Introduction, or it can simply $\beta$-scission a $\mathrm{C}-\mathrm{C}$ bond to form the benzyl radical, $\mathrm{C}_{7} \mathrm{H}_{7}$ (p10), and ethene, $\mathrm{C}_{2} \mathrm{H}_{4}$. It is because of the latter product channel, benzyl radical + $\mathrm{C}_{2} \mathrm{H}_{4}$, that the aromatic-catalyzed 1,2-H-migration was inferred from experiments described in the following sections.

The aromatic-catalyzed 1,2-H-migration proceeds in two steps. First i1 undergoes a 1,4-H-migration, transferring one of the H's on an ortho-carbon to the secondary carbon radical
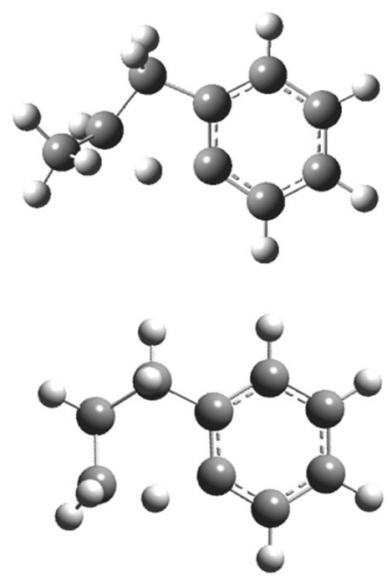

Fig. 1 Optimized structures of transition states involved in aromaticcatalyzed 1,2-hydrogen-migration: 5-membered-ring intramolecular hydrogen-migration TS connecting i1 and i12 (top), and 6-memberedring intramolecular hydrogen-migration TS connecting i12 to i4.

on the alkyl side-chain via a 5-membered-ring TS (Fig. 1). The barrier for this first, rate-limiting step in the aromatic-catalyzed 1,2-H-migration is energetically similar to the barrier for $\beta$-scission of $\mathrm{CH}_{3}$ from i2 $\left(\sim 30 \mathrm{kcal} \mathrm{mol}^{-1}\right)$, which is known to be a major loss channel for equilibrated i1/i2. The new intermediate formed (i12) has a radical site on an orthocarbon and a fully saturated propyl side-chain. i12 can then undergo a 1,5-H-migration, transferring one of the H's on the primary carbon at the end of the alkyl side-chain back to the ortho-carbon via a low barrier $\left(\sim 8 \mathrm{kcal} \mathrm{mol}^{-1}\right)$ 6-memberedring TS (Fig. 1) forming i4. To summarize, an overall reaction $(\mathbf{i 1} \rightarrow$ i4) that has a high barrier as a one-step process $(1,2-\mathrm{H}-$ shift) is more energetically feasible as a two-step process $(1,4-\mathrm{H}$ shift $+1,5-\mathrm{H}$-shift) enabled by the presence of a catalyst that is unaltered at the end of the process (the phenyl side group). Hence, the two-step $\mathbf{i 1} \rightarrow \mathbf{i 1 2} \rightarrow \mathbf{i} 4$ process was given the name "aromatic-catalyzed" 1,2-H-shift in acknowledgement of the central role of the aromatic side group (phenyl in this case) as both a source and a sink of the $\mathrm{H}$-atom, much like a conventional Bronsted acid catalyst that acts as both source and sink of protons. This pathway is accessible to many radicals containing aromatic-groups as long as there is an $\mathrm{H}$ on at least one orthocarbon site. The second step is fast if there is at least one $\mathrm{H}$ on a carbon in the chain in a $\beta, \gamma$ or $\delta$ position relative to the aromatic group.

Given the favourable energetics of the previously unreported aromatic-catalyzed 1,2-H-shift, it was deemed worthwhile to revisit calculations of the $\mathrm{C}_{6} \mathrm{H}_{5}+\mathrm{C}_{3} \mathrm{H}_{6}$ product branching under both thermal ( $T, P$, see Fig. 2) and single-collision ( $E$, see Fig. 4) conditions, and to re-assess previous experimental results in this new context.

The thermal product branching was calculated by simulating the network of Cantherm-generated phenomenological $k(T, P)$ 's on the $\mathrm{C}_{9} \mathrm{H}_{11}$ PES in an isothermal, isobaric, homogeneous batch reactor in CHEMKIN $^{35}$ for 50 milliseconds. The initial $\mathrm{C}_{6} \mathrm{H}_{5}$ and $\mathrm{C}_{3} \mathrm{H}_{6}$ concentrations were kept fixed at $3 \times 10^{12}$ and 
$5 \times 10^{16} \mathrm{~cm}^{-3}$, respectively, for all $T, P$ conditions, with the helium bath gas providing the balance of the gas density. These specific reaction conditions were chosen to closely simulate the conditions of the experiment reported in this work in order to facilitate comparison. The $k(T, P)$ 's taken from Cantherm include both thermally activated, well-to-well rates (i1 $\rightarrow$ i3, for example) and chemically activated, well-skipping rates (i1 $\rightarrow$ p10 $+\mathrm{C}_{2} \mathrm{H}_{4}$, for example). When simulated together, the combined thermally and chemically activated $k(T, P)$ 's provide a complete picture of the initial chemical evolution of the thermal system, neglecting side and secondary reactions not on the same PES (considered later).

Qualitatively, the thermal product branching shown in Fig. 2 is very similar to that calculated by Kislov et al., ${ }^{11}$ albeit their definition of product branching is slightly different. At low- $T$ stabilized i1 dominates the product distribution, but from 600 to $1000 \mathrm{~K}$ styrene, p1, becomes the prominent product. With a further increase in $T$, branching to $\mathbf{p} \mathbf{1}$ gradually decreases to be replaced mostly with $\mathrm{C}_{6} \mathrm{H}_{6}$ from the three $\mathrm{H}$-abstraction channels. Unlike the predictions of Kislov et al., a peak branching
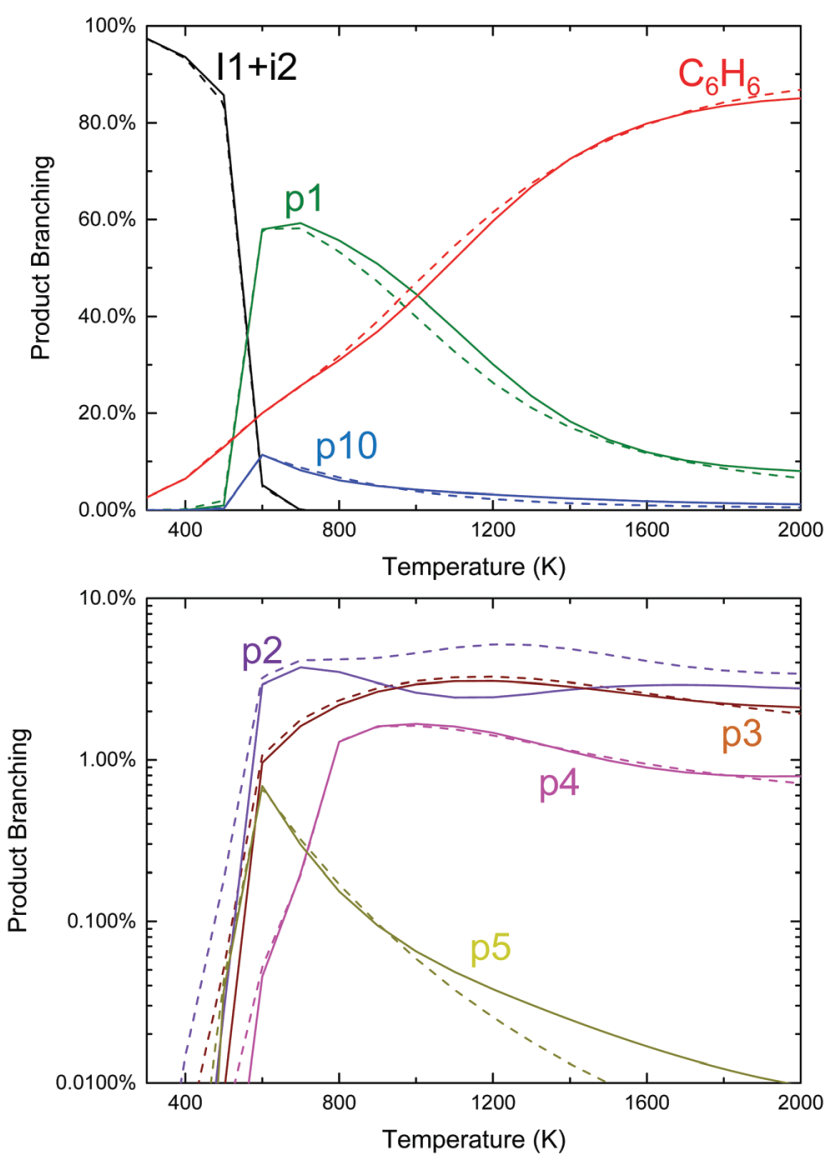

Fig. 2 Predicted product branching of phenyl radical + propene on a linear (top, products with $>10 \%$ branching) and logarithmic (bottom, products with $<10 \%$ branching) scale as a function of $T$ and $P$ for otherwise fixed conditions: 50 millisecond reaction time, $\left[\mathrm{C}_{3} \mathrm{H}_{6}\right]=5 \times$ $10^{16} \mathrm{~cm}^{-3}$ and $\left[\mathrm{C}_{6} \mathrm{H}_{5}\right]_{0}=3 \times 10^{12} \mathrm{~cm}^{-3}$ ( $[\mathrm{He}]$ provides the balance of the gas density). Dashed lines are predictions at 10 Torr and solid lines are 1000 Torr. of $\sim 10 \%$ benzyl radical, p10, is predicted at $\sim 600 \mathrm{~K}$ and like styrene diminishes with $T$. Given the chemical complexity of previous thermal experiments probing $\mathrm{C}_{6} \mathrm{H}_{5}+\mathrm{C}_{3} \mathrm{H}_{6}$, ${ }^{6,10}$ the lack of observable benzyl radical in those works could easily be attributed to side reactions. However, in the product mass spectrum reported by Zhang et al. there is a peak at $m / z=91$ amu (mass of the benzyl radical) though it is not discussed. ${ }^{10}$

Also unlike Kislov et al., the predicted pressure dependence from 10 to 1000 Torr over the whole $T$-range is negligible. This prediction was not sensitive to the choice of CET parameters or the method used to solve the ME. ${ }^{33}$ The discrepancy with Kislov et al. is likely due to the difference in the definition of product branching, specifically the inclusion of both thermally and chemically activated pathways in the simulation. The predicted lack of $P$-dependence is shown to be consistent with experiments in Section 4.3.

Finally, although the branching to indane, p5, is about an order of magnitude higher than in Kislov et al. due to the aromatic-catalyzed 1,2-H-shift promoting isomerization to i4, the overall amount of $\mathbf{p 5}$ formed is still small ( $\sim 1 \%$ peak), consistent with the experiments of Zhang et al. ${ }^{10}$ Overall, the predicted thermal product branching reported here does not significantly alter the current understanding of $\mathrm{C}_{6} \mathrm{H}_{5}+\mathrm{C}_{3} \mathrm{H}_{6}$ (styrene, phenylpropene isomers and benzene are all still major products) other than the inclusion of a non-negligible, pressure-independent $\sim 10 \%$ yield of benzyl radical and $\mathrm{C}_{2} \mathrm{H}_{4}$.

An approach identical to Kaiser et $a l^{9}$ for quantifying product branching under single-collision conditions was taken here and has already been described in the Theoretical section. Just as in the thermal case, the single-collision product branching shown in Fig. 4 is very similar to what has previously been reported, this time by Kaiser et al., with some important exceptions. In terms of similarities, p1 dominates at low $E_{\text {col }}$ and is gradually replaced by $\mathbf{p} 2$ with increasing $E_{\text {col }}$. This was the same qualitative observation made by all three CMB experiments regarding the effect of $E_{\text {col }}$ on the $\mathrm{CH}_{3}$-loss to $\mathrm{H}$-loss ratio. $^{8,9,12}$ One main difference is that there is up to $\sim 15 \%$ branching to the benzyl radical, p10, at the lowest $E_{\text {col }}$, followed by a steady decline. Considering that all of the CMB experiments were conducted at $E_{\mathrm{col}} \geq 10 \mathrm{kcal} \mathrm{mol}^{-1}$, any $\mathbf{p 1 0}$ formed in those experiments was likely below the detection limit. The other important difference is an increased yield of p5 (up to $3 \%$ ), but that would have also been too small to detect in the CMB experiments, making it consistent with the observations made therein. ${ }^{8,9}$

To conclude this section, although the newly discovered aromatic-catalyzed 1,2-H-migration is predicted to be both energetically and kinetically competitive with the other reactions on the $\mathrm{C}_{9} \mathrm{H}_{11}$ PES available to $\mathrm{C}_{6} \mathrm{H}_{5}+\mathrm{C}_{3} \mathrm{H}_{6}$, none of the six previously published experiments on this system have seen clear evidence for it. In the case of the thermal experiments this is either because of complex chemistry with side and secondary reactions, ${ }^{6,10}$ or because the detection technique was not intended for product measurements, as in the CRDS experiments of Park et al. ${ }^{7}$ In the case of the CMB experiments, detection sensitivity is the issue. Most of the remainder of this work will present experimental 
measurements coupled with detailed modelling that together quantitatively support the predictions above.

\subsection{Overall $k(T)$ measured by $505.3 \mathrm{~nm}$ absorbance}

In addition to MBMS and laser absorbance experiments to quantify product branching, discussed in the following sections, $505.3 \mathrm{~nm}$ absorbance of $\mathrm{C}_{6} \mathrm{H}_{5}$ was also used to measure the total consumption rate coefficient, $k_{\text {total }}(T)$, of $\mathrm{C}_{6} \mathrm{H}_{5}$. These measurements of $k_{\text {total }}(T)$ are presented first because later results depend on them.

$\mathrm{C}_{6} \mathrm{H}_{5}$ is known to have a low-lying electronic transition at $504.8 \mathrm{~nm}$ at room temperature, ${ }^{14}$ but in this work $505.3 \mathrm{~nm}$ was used to probe $\mathrm{C}_{6} \mathrm{H}_{5}$ under all $T, P$ conditions due to slightly higher absorbance observed at that wavelength. The other radicals formed in the $\mathrm{C}_{6} \mathrm{H}_{5}+\mathrm{C}_{3} \mathrm{H}_{6}$ system $\left(\mathrm{CH}_{3},{ }^{36} \mathrm{C}_{3} \mathrm{H}_{5}{ }^{37}\right.$ and $\mathrm{C}_{7} \mathrm{H}_{7}{ }^{38}$ ) are not expected to absorb significantly at such a relatively long wavelength. Therefore, $\mathrm{C}_{6} \mathrm{H}_{5}$ can be probed selectively at $505.3 \mathrm{~nm}$. However, as mentioned earlier, if $\mathrm{O}_{2}$ is present in the reactor at a similar concentration as $\mathrm{C}_{6} \mathrm{H}_{5}$, $\mathrm{C}_{6} \mathrm{H}_{5} \mathrm{OO}$ will also absorb strongly and broadly at $\sim 500 \mathrm{~nm},{ }^{25}$ providing a convenient leak indicator.

$k_{\text {total }}(T)$ consists of contributions from five different $\mathrm{C}_{6} \mathrm{H}_{5}+$ $\mathrm{C}_{3} \mathrm{H}_{6}$ entrance channels (two radical additions and three $\mathrm{H}$-abstractions):

$$
\begin{aligned}
\mathrm{C}_{6} \mathrm{H}_{5}+\mathrm{C}_{3} \mathrm{H}_{6} & \rightarrow \mathrm{i} 1 \\
& \rightarrow \mathbf{i} 2 \\
& \rightarrow \mathrm{C}_{6} \mathrm{H}_{6}+\mathrm{CH}_{2} \mathrm{CHCH}_{2} \text { (allyl radical, } \mathrm{C}_{3} \mathrm{H}_{5} \text { ) } \\
& \rightarrow \mathrm{C}_{6} \mathrm{H}_{6}+\mathrm{CH}_{3} \mathrm{CCH}_{2} \\
& \rightarrow \mathrm{C}_{6} \mathrm{H}_{6}+\mathrm{CH}_{2} \mathrm{CHCH}
\end{aligned}
$$

From the calculations of the barrier heights for these five elementary reactions (Fig. 3) it is expected that terminal radical addition to form i1 (1.4 kcal mol ${ }^{-1}$ barrier) will dominate $\mathrm{C}_{6} \mathrm{H}_{5}$ consumption, followed by central addition to i2 $\left(2.6 \mathrm{kcal} \mathrm{mol}^{-1}\right)$ and $\mathrm{H}$-abstraction from the allylic carbon (3.6 kcal $\left.\mathrm{mol}^{-1}\right)$. The other two H-abstractions have higher barriers (6.4 and $8.4 \mathrm{kcal} \mathrm{mol}^{-1}$ ) and are predicted to be negligible below $1000 \mathrm{~K}$.

Background absorbance traces are recorded with He only (or He and $\mathrm{C}_{3} \mathrm{H}_{6}$ only) following photolysis to account for spurious absorbance, which is likely due to heating of the Herriott cell optics from scattered photolysis light and subsequent steering of the probe laser beam slightly off of the signal photodiode. The background absorbance was subtracted from absorbance traces recorded with $\mathrm{C}_{6} \mathrm{H}_{5}$ present.

Each background-subtracted and normalized $505.3 \mathrm{~nm}$ absorbance trace was fit to an exponential decay assuming pseudo-first-order kinetics:

$$
\begin{gathered}
A(t) / A_{0}=(1-a) \mathrm{e}^{-k^{\prime} t}+a \\
k^{\prime}=k_{\text {total }}\left[\mathrm{C}_{3} \mathrm{H}_{6}\right]+k_{\text {wall }}
\end{gathered}
$$

$a$ is a vertical shift factor to account for slight offsets (usually $\pm 10 \%$ ) in the baseline due to noise, imperfect background subtraction and artifacts from the AC-coupled detection electronics. $k^{\prime}$ is the pseudo-first-order decay rate, which consists of a contribution from $\mathrm{C}_{6} \mathrm{H}_{5}+\mathrm{C}_{3} \mathrm{H}_{6}$ and from $k_{\text {wall }} \cdot k_{\text {wall }}$ is a fit parameter that accounts for all of the other $\mathrm{C}_{6} \mathrm{H}_{5}$ loss processes (wall reaction, self-reaction, reaction with impurities like $\mathrm{O}_{2}$, reaction with the precursor, transport out of the sampling volume, etc.). Fig. 5 shows representative $505.3 \mathrm{~nm}$ absorbance traces fit to exponential decays.

Table 2 summarizes the conditions of the fourteen $505.3 \mathrm{~nm}$ absorbance experiments. Each experiment was conducted at a fixed $T$ and $P$, and consisted of at least five absorbance traces at different concentrations of propene, $\left[\mathrm{C}_{3} \mathrm{H}_{6}\right]$. The nominal $T$ was varied from 300 to $700 \mathrm{~K}$, and $P$ was mostly kept at 10 Torr,

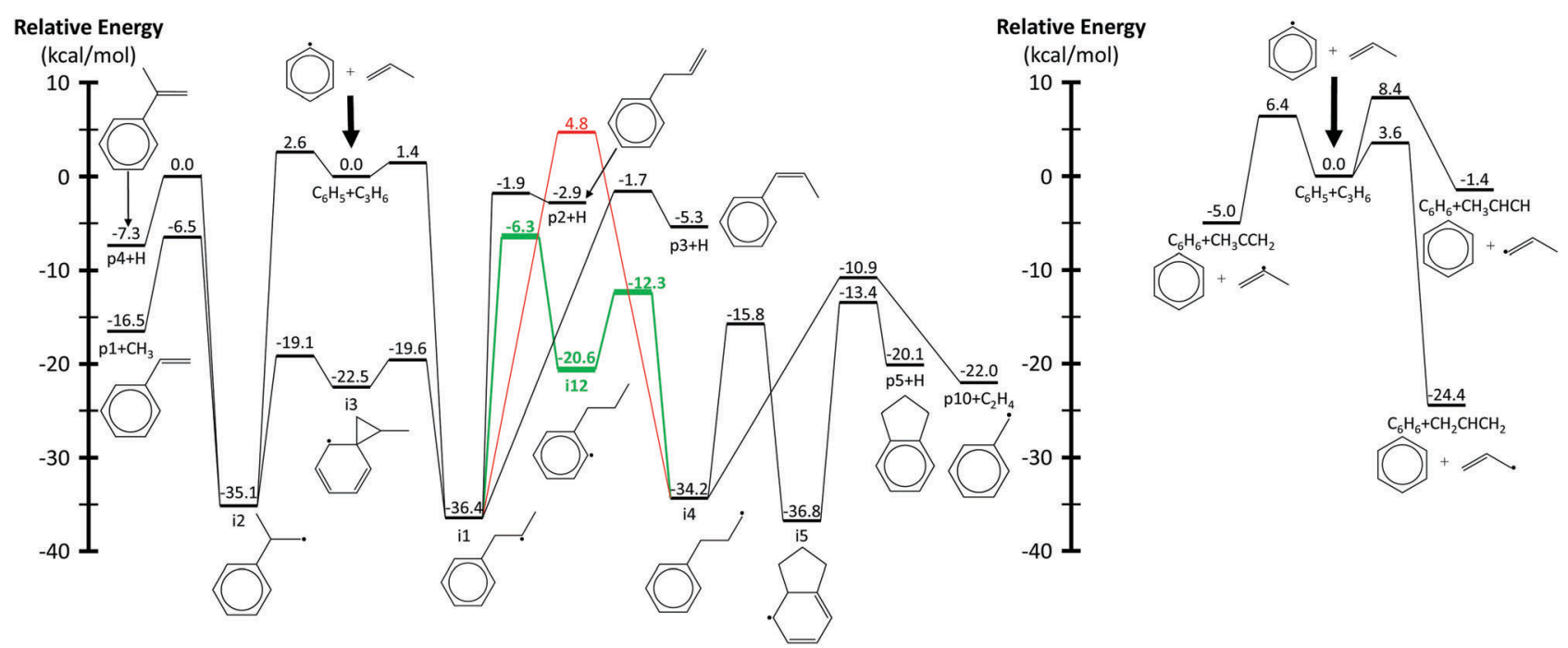

Fig. 3 Simplified phenyl radical + propene PES calculated using G3(MP2,CC)//B3LYP/6-311G(d,p). Radical addition pathways are shown on the left and hydrogen abstraction on the right. The direct and aromatic-catalyzed 1,2-hydrogen-migrations are highlighted in red and green, respectively. Energies and geometries for all stationary points were calculated by Kislov et al., ${ }^{11}$ except for those in green and the $\beta$-scission of i4 to p10 + $\mathrm{C}_{2} \mathrm{H}_{4}$, which were calculated in this work. 

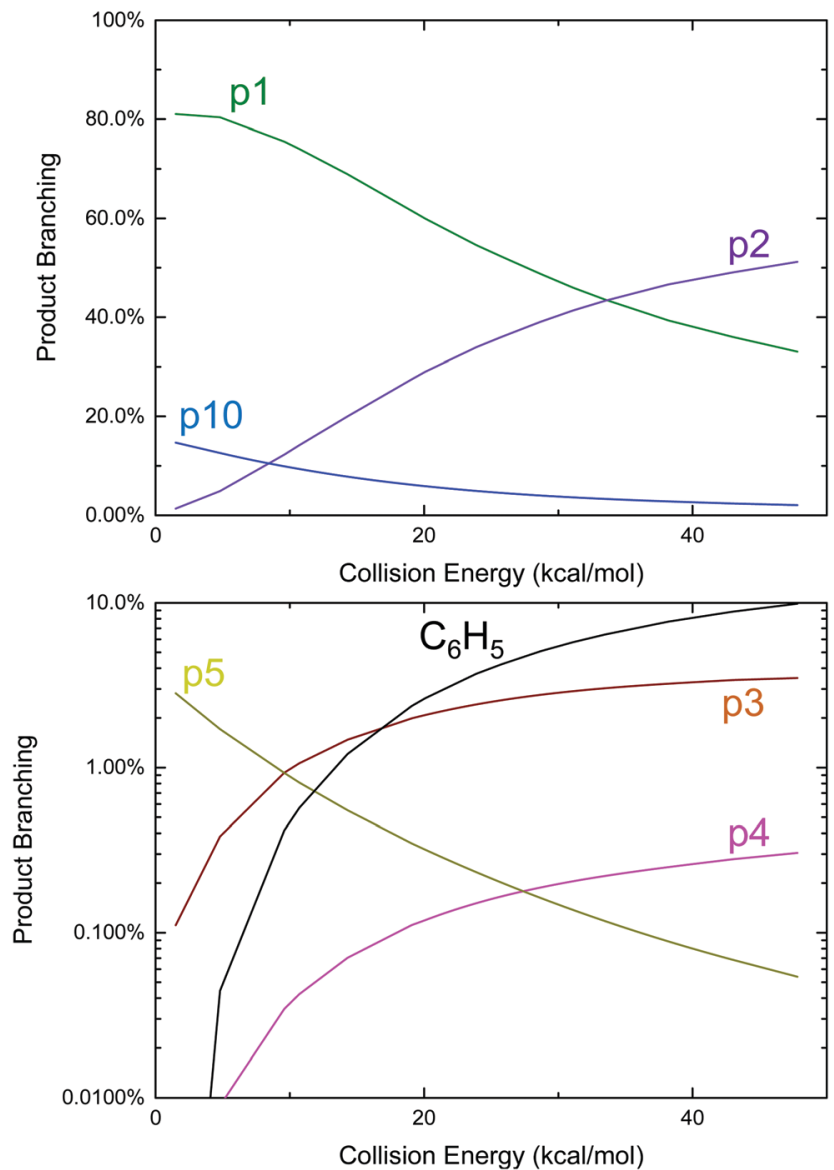

Fig. 4 Predicted product branching of phenyl radical + propene on a linear (top, products with $>10 \%$ branching) and logarithmic (bottom, products with $<10 \%$ branching) scale as a function of collision energy under single-collision conditions.

except for one control experiment at 25 Torr to demonstrate the independence of $k_{\text {total }}(T)$ from $P . \mathrm{C}_{6} \mathrm{H}_{5} \mathrm{I}$ was used as the photolytic $\mathrm{C}_{6} \mathrm{H}_{5}$ precursor in all but two of the experiments for the three reasons mentioned in the Experimental section. Initial radical concentrations were quantified by single-pass IR absorbance of the I atom, following the same procedure described previously. ${ }^{41,42}$ For a given experiment, $\left[\mathrm{C}_{3} \mathrm{H}_{6}\right]$ was varied over a wide range to verify a linear relationship with $k^{\prime}$. Some of the fit $k_{\text {wall }}$ values are rather large $\left(>1000 \mathrm{~s}^{-1}\right)$, likely due to a small air leak during those experiments that was later fixed (importantly, all of the MBMS results presented in the next section were obtained without the leak). However, in all experiments $\left[\mathrm{C}_{3} \mathrm{H}_{6}\right]$ was increased such that the decay of $\mathrm{C}_{6} \mathrm{H}_{5}$ due to $\mathrm{C}_{6} \mathrm{H}_{5}+\mathrm{C}_{3} \mathrm{H}_{6}$ was $5-10 \times$ the contribution of $k_{\text {wall }}$. The vertical shift factor, $a$, was usually between -0.1 and 0.1 , and in the worst case it was -0.25 . Besides varying the precursor identity and $P$, control experiments were also conducted using different photolysis laser fluences, precursor concentrations, radical concentrations, and flashes per refresh (FPR), in order to verify the independence of a given $k_{\text {total }}(T)$ from all of these parameters. The reported uncertainty in $k_{\text {total }}(T)$ is at least $10 \%$ due to possible systematic uncertainty in $\left[\mathrm{C}_{3} \mathrm{H}_{6}\right]$, as well as

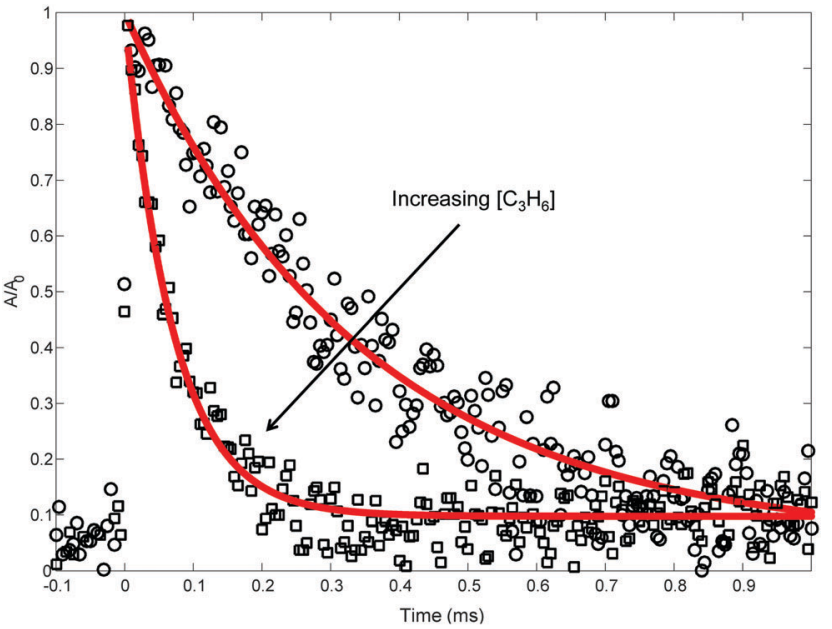

Fig. 5 Representative $505.3 \mathrm{~nm}$ absorbance decays measured (markers) at $691 \mathrm{~K}, 10$ Torr. Lines are exponential fits. Only every 10th point is shown for clarity.

fitting uncertainty. ${ }^{21}$ For all experiments, the overlap pathlength between the Herriott cell and the photolysis laser was $\sim 20 \mathrm{~m}$. The absolute $505.3 \mathrm{~nm}$ absorbance signal observed for a given $[\mathrm{I}]_{0}\left(=\left[\mathrm{C}_{6} \mathrm{H}_{5}\right]_{0}\right)$ was consistent with a $\mathrm{C}_{6} \mathrm{H}_{5}$ cross-section of $\sim 2 \times 10^{-19} \mathrm{~cm}^{2}$ under all conditions, similar to the measurement of Tonokura et al. ${ }^{14}\left(3.6 \pm 1.6 \times 10^{-19} \mathrm{~cm}^{2}\right.$ at $504.8 \mathrm{~nm}$ and $298 \mathrm{~K}$ ).

Fig. 6 compares the fourteen measurements of $k_{\text {total }}(T)$ in this work against the previous measurements of Park et al. using CRDS. ${ }^{7}$ The two sets of measurements agree well with each other, including the various control experiments. By using a different chemical precursor that does not significantly thermally decompose at $<900 \mathrm{~K}\left(\mathrm{C}_{6} \mathrm{H}_{5} \mathrm{I}\right),{ }^{26}$ this work is able to extend the upper $T$ at which $k_{\text {total }}(T)$ is measured by $\sim 200 \mathrm{~K}$ compared to the previous work $\left(\mathrm{C}_{6} \mathrm{H}_{5} \mathrm{NO},<700 \mathrm{~K}^{24}\right)$.

Also shown is the predicted $k_{\text {total }}(T)$, obtained by summing the TST calculated rate coefficients for the five different entrance channels. The barrier for terminal addition had to be lowered by $0.75 \mathrm{kcal} \mathrm{mol}^{-1}$ in order to obtain the agreement between experiment and theory shown in Fig. 6. As expected, terminal addition to i1 is predicted to be the dominant entrance channel, especially at lower $T$, with central addition and allylic $\mathrm{H}$-abstraction $\sim 1-2$ orders of magnitude slower over the experimental range. The calculated entrance rates in Fig. 6 (including the adjusted rate for terminal addition) were used in all subsequent $\mathrm{C}_{6} \mathrm{H}_{5}+\mathrm{C}_{3} \mathrm{H}_{6}$ models discussed in the following sections.

\subsection{Products measured by MBMS}

Table 3 summarizes the conditions of the 15 MBMS experiments. Only nominal temperatures of 600 and $700 \mathrm{~K}$ were explored because for $T<600 \mathrm{~K}$ secondary reactions involving the I atom will dominate the reaction flux (discussed later). Also, at lower $T$ a higher $\left[\mathrm{C}_{3} \mathrm{H}_{6}\right]$ is needed to ensure fast and near-unity reaction of $\mathrm{C}_{6} \mathrm{H}_{5}$ with $\mathrm{C}_{3} \mathrm{H}_{6}$, but higher $\left[\mathrm{C}_{3} \mathrm{H}_{6}\right]$ tends to lower the MBMS sensitivity both due to attenuation of VUV photons and due to a decrease in the density of the molecular 
Table 2 Summary of $505.3 \mathrm{~nm}$ absorbance experiments. Uncertainties represent two standard deviations

\begin{tabular}{|c|c|c|c|c|c|c|c|c|c|c|c|c|}
\hline Exp. \# & $\begin{array}{l}\text { Nominal } \\
T(\mathrm{~K})\end{array}$ & Real $T(\mathrm{~K})$ & $\begin{array}{l}P \\
\text { (Torr) }\end{array}$ & $\mathrm{X}^{a}$ & $\begin{array}{l}{\left[\mathrm{C}_{6} \mathrm{H}_{5} \mathrm{X}\right]^{b, c}} \\
\left(10^{13} \mathrm{~cm}^{-3}\right)\end{array}$ & $\begin{array}{l}F^{d} \\
\left(\mathrm{~mJ} \mathrm{~cm}{ }^{-2}\right)\end{array}$ & $\begin{array}{l}{\left[\mathrm{C}_{3} \mathrm{H}_{6}\right]^{b} \text { range }} \\
\left(10^{15} \mathrm{~cm}^{-3}\right)\end{array}$ & $\begin{array}{l}\text { IR }[\mathrm{I}]_{0} \\
\left(10^{12} \mathrm{~cm}^{-3}\right)\end{array}$ & $\begin{array}{l}\text { \# of } \\
\text { traces }\end{array}$ & $\begin{array}{l}k_{\text {total }}^{e} \\
\left(\times 10^{-14}\right)\end{array}$ & $k_{\text {wall }}^{e}$ & Range of $a^{f}$ \\
\hline 1 & 300 & $295.3 \pm 0.4$ & 10 & I & 6.5 & 15 & $26.8-215$ & $3.5 \pm 1$ & 7 & $1.1 \pm 0.1$ & 550 & -0.02 to 0.05 \\
\hline 2 & 300 & $295.3 \pm 0.4$ & 10 & I & 13.0 & 15 & $13.4-215$ & $6 \pm 2$ & 7 & $1.1 \pm 0.1$ & 690 & 0.002 to 0.06 \\
\hline 3 & 300 & $295.3 \pm 0.4$ & 10 & I & 6.5 & 30 & $26.8-215$ & $6 \pm 2$ & 6 & $1.3 \pm 0.1$ & 520 & -0.09 to 0.10 \\
\hline $4^{g}$ & 300 & $295.3 \pm 0.4$ & 10 & I & 6.5 & 15 & $26.8-215$ & $3 \pm 1$ & 7 & $1.2 \pm 0.1$ & 390 & -0.09 to 0.04 \\
\hline 5 & 400 & $394 \pm 4$ & 10 & I & 6.1 & 15 & $25.4-152$ & $3 \pm 1$ & 6 & $3.0 \pm 0.3$ & 720 & -0.06 to 0.10 \\
\hline 6 & 500 & $494 \pm 8$ & 10 & I & 6.1 & 15 & $20.1-120$ & $3 \pm 1$ & 6 & $6.3 \pm 0.8$ & 600 & -0.11 to 0.10 \\
\hline 7 & 600 & $589 \pm 14$ & 10 & I & 5.6 & 15 & $11.5-69.0$ & $2.5 \pm 1$ & 6 & $13.3 \pm 1.6$ & 400 & -0.09 to 0.14 \\
\hline 8 & 700 & $691 \pm 16$ & 10 & I & 5.9 & 15 & $9.8-58.6$ & $3 \pm 1$ & 6 & $19.4 \pm 2.5$ & 1700 & -0.08 to 0.09 \\
\hline 9 & 700 & $691 \pm 16$ & 25 & I & 6.2 & 15 & $10.3-61.8$ & $3 \pm 1$ & 6 & $18.7 \pm 2.2$ & 600 & 0.0 to 0.08 \\
\hline 10 & 700 & $691 \pm 16$ & 10 & I & 11.8 & 15 & $4.9-24.4$ & $6 \pm 2$ & 5 & $20.5 \pm 2.5$ & 1700 & -0.08 to 0.12 \\
\hline 11 & 700 & $691 \pm 16$ & 10 & I & 5.9 & 30 & $9.8-58.6$ & $6 \pm 2$ & 6 & $20.8 \pm 2.5$ & 2000 & -0.25 to 0.02 \\
\hline $12^{g}$ & 700 & $691 \pm 16$ & 10 & I & 5.9 & 15 & $9.8-58.6$ & $4 \pm 2$ & 6 & $18.0 \pm 2.1$ & 1100 & -0.12 to 0.12 \\
\hline 13 & 300 & $295.3 \pm 0.4$ & 10 & NO & 0.6 & 4 & $25.8-301$ & - & 6 & $1.3 \pm 0.1$ & 80 & -0.03 to 0.13 \\
\hline 14 & 500 & $494 \pm 8$ & 10 & NO & 0.6 & 4 & $25.1-150$ & - & 5 & $6.1 \pm 0.9$ & 1600 & 0.03 to 0.11 \\
\hline
\end{tabular}

${ }^{a}$ Identity of $\mathrm{X}$ in the precursor, $\mathrm{C}_{6} \mathrm{H}_{5} \mathrm{X} .{ }^{b} 10 \%$ uncertainty in all values due to systematic uncertainty in mass flow controller calibrations. ${ }^{c}$ Precursor concentrations calculated assuming that He exiting the bubbler is saturated with $\mathrm{C}_{6} \mathrm{H}_{5} \mathrm{X}$ at its room temperature vapor pressure: 0.92 Torr for $\mathrm{C}_{6} \mathrm{H}_{5} \mathrm{I}^{39}$ and 0.6 Torr for $\mathrm{C}_{6} \mathrm{H}_{5} \mathrm{NO}^{40}{ }^{d}$ Photolysis laser fluence. ${ }^{e}$ Units are molecule, $\mathrm{s}, \mathrm{cm} .{ }^{f}$ Vertical shift factor in fits to normalized absorbance traces. ${ }^{g}$ Repetition rate of the photolysis laser doubled to $2 \mathrm{~Hz}$ to check the effect of flashes per refresh (FPR).

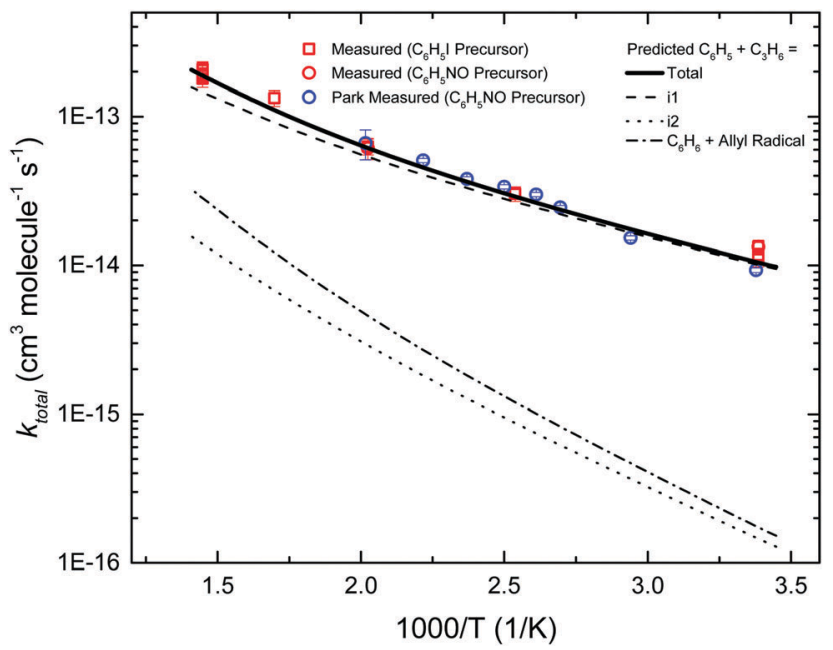

Fig. 6 Measured (markers) and predicted (lines) kinetics of phenyl radical + propene entrance reactions

beam for a heavier carrier gas. ${ }^{43} P$ was 10 Torr for all of the experiments except for two conducted at 25 Torr and another two conducted at 50 Torr to test the effect of pressure on the product distribution.

For a given $T, P$-condition, the time-dependent product branching was typically measured over four different $\left[\mathrm{C}_{3} \mathrm{H}_{6}\right]$, including an experiment without $\mathrm{C}_{3} \mathrm{H}_{6}$. Control experiments were also conducted at different photolysis laser fluence, precursor concentration and radical concentration to check the effect of these variables. Both $505.3 \mathrm{~nm}$ absorbance of $\mathrm{C}_{6} \mathrm{H}_{5}$ and IR absorbance of the I atom were measured simultaneously with all of the MBMS experiments.

Fig. 8 shows representative, time-resolved mass spectra that have had the pre-photolysis background subtracted out so that only transient signals are observed. The spectra are divided into two $\mathrm{m} / \mathrm{z}$ regions for clarity: a lower range from 70 to $125 \mathrm{amu}$ where all of the primary $\mathrm{C}_{6} \mathrm{H}_{5}+\mathrm{C}_{3} \mathrm{H}_{6}$ product signals appear, and a higher range from 125 to $250 \mathrm{amu}$ where the side and secondary product signals appear, many of them corresponding to iodide-containing species. No transient signals were observed below $77 \mathrm{amu}\left(\mathrm{C}_{6} \mathrm{H}_{5}\right)$ for any experiment. Qualitatively, all of the primary $\mathrm{C}_{6} \mathrm{H}_{5}+\mathrm{C}_{3} \mathrm{H}_{6}$ products (see Fig. 2 for prediction of product branching) are observed at their expected parent $m / z$ : $78 \mathrm{amu}$ for $\mathrm{C}_{6} \mathrm{H}_{6}, 91 \mathrm{amu}$ for $\mathbf{p 1 0}$ (benzyl radical), $104 \mathrm{amu}$ for p1 (styrene), 118 amu for p2-p4 (phenylpropene isomers) and $119 \mathrm{amu}$ for i1 and i2. It should be reiterated that initially the $91 \mathrm{amu}$ product was unexpected based on the previous $\mathrm{C}_{6} \mathrm{H}_{5}+$ $\mathrm{C}_{3} \mathrm{H}_{6}$ literature, but can now be rationalized by the aromaticcatalyzed 1,2-H-migration that facilitates p10 formation discussed in Section 4.1. The side and secondary products can also be assigned intuitively: 127 and 128 amu correspond to the I atom and HI, $134 \mathrm{amu}$ is the recombination product of $\mathbf{i 1}+$ $\mathrm{CH}_{3}$ (named i1- $\left.\mathrm{CH}_{3}\right), 142 \mathrm{amu}$ is methyl iodide $\left(\mathrm{CH}_{3} \mathrm{I}\right), 154 \mathrm{amu}$ is biphenyl $\left(\mathrm{C}_{6} \mathrm{H}_{5}-\mathrm{C}_{6} \mathrm{H}_{5}\right), 168 \mathrm{amu}$ is allyl iodide $\left(\mathrm{C}_{3} \mathrm{H}_{5} \mathrm{I}\right)$ and $246 \mathrm{amu}$ is the recombination product of i1 + I (named i1-I). There is also a small transient signal at $m / z=160 \mathrm{amu}$ that is difficult to discern in Fig. 8 corresponding to i1 + allyl radical (named i1- $\mathrm{C}_{3} \mathrm{H}_{5}$ ).

All of the transient MBMS signals were integrated and plotted against reaction time, as shown for three representative experiments in Fig. 7 (experiments \#2, 7 and 15). The thick solid lines in those plots correspond to model predictions, which will be described in the following section. Qualitatively, there are several features of Fig. 7 that are consistent with the product branching predictions of Fig. 2. First, the product branching has a strong dependence on $T$, which can be seen by comparing experiments $\# 2$ and 7, conducted at nominal $T$ 's of 600 and $700 \mathrm{~K}$, respectively, and 10 Torr. Second, p1 $(104 \mathrm{amu})$ is the dominant product at $700 \mathrm{~K}$, assuming similar photoionization cross sections (PICS) for all products. The $104 \mathrm{amu}$ signal is $3-4 \times$ any of the other product signals, which is in nearly quantitative agreement with Fig. 2. Third, $\mathrm{C}_{6} \mathrm{H}_{6}$ is clearly observed as a primary product. The importance of $\mathrm{C}_{6} \mathrm{H}_{6}$ with increasing $T$ was predicted both here and in Kislov et al. ${ }^{11}$ but has never before been directly confirmed experimentally and 
Table 3 Conditions of MBMS experiments. Uncertainties represent two standard deviations

\begin{tabular}{|c|c|c|c|c|c|c|c|c|c|c|}
\hline $\begin{array}{l}\text { Experiment } \\
\#\end{array}$ & $\begin{array}{l}\text { Nominal } \\
T(\mathrm{~K})\end{array}$ & Real $T(\mathrm{~K})$ & $P$ (Torr) & $\begin{array}{l}{\left[\mathrm{C}_{3} \mathrm{H}_{6}\right]^{a}} \\
\left(10^{15} \mathrm{~cm}^{-3}\right)\end{array}$ & $\begin{array}{l}{\left[\mathrm{C}_{6} \mathrm{H}_{5} \mathrm{I}\right]^{a}} \\
\left(10^{13} \mathrm{~cm}^{-3}\right)\end{array}$ & $\begin{array}{l}\text { IR } \mathrm{C}_{\mathrm{I}, 0} \\
\left(10^{12} \mathrm{~cm}^{-3}\right)\end{array}$ & $\begin{array}{l}\mathrm{MS} \mathrm{C}_{\mathrm{I}, 0} \\
\left(10^{12} \mathrm{~cm}^{-3}\right)\end{array}$ & $\begin{array}{l}\text { Photolysis laser } \\
\text { fluence }\left(\mathrm{mJ} \mathrm{cm}^{-2}\right)\end{array}$ & $k_{\text {sampling }}{ }^{b}\left(\mathrm{~s}^{-1}\right)$ & $c^{c}$ \\
\hline 1 & 600 & $605 \pm 4$ & 10 & 0 & 6.1 & $2 \pm 0.8$ & $1 \pm 0.5$ & 14 & 1500 & 0 \\
\hline 2 & 600 & $605 \pm 4$ & 10 & 7.5 & 6.1 & $2 \pm 0.8$ & $1 \pm 0.5$ & 14 & 1000 & 0.32 \\
\hline 4 & 600 & $605 \pm 4$ & 10 & 30.0 & 6.1 & $2 \pm 0.8$ & $1 \pm 0.5$ & 14 & 1000 & 0.69 \\
\hline 5 & 600 & $605 \pm 4$ & 10 & 15.0 & 12.1 & $3.5 \pm 1.2$ & $1.5 \pm 0.75$ & 14 & 1000 & 0.46 \\
\hline 6 & 700 & $707 \pm 6$ & 10 & 0 & 5.9 & $3 \pm 1.2$ & $1 \pm 0.5$ & 14 & 1500 & 0 \\
\hline 9 & 700 & $707 \pm 6$ & 10 & 29.0 & 4.1 & $3 \pm 1.2$ & $1.5 \pm 0.75$ & 20 & 750 & 0.86 \\
\hline 10 & 700 & $707 \pm 6$ & 10 & 15.0 & 11.9 & $3 \pm 1.2$ & $1 \pm 0.5$ & 7 & 750 & 0.53 \\
\hline 11 & 700 & $707 \pm 6$ & 10 & 15.0 & 11.9 & $5 \pm 1.7$ & $2 \pm 1.0$ & 14 & 750 & 0.51 \\
\hline 12 & 700 & $700 \pm 6$ & 25 & 0 & 5.9 & $2.5 \pm 1.0$ & $1 \pm 0.5$ & 14 & 750 & 0 \\
\hline 13 & 700 & $700 \pm 6$ & 25 & 7.2 & 5.9 & $2.5 \pm 1.0$ & $1 \pm 0.5$ & 14 & 600 & 0.3 \\
\hline 14 & 700 & $687 \pm 5$ & 50 & 0 & 6.1 & $2 \pm 1.0$ & $1 \pm 0.5$ & 14 & 800 & 0 \\
\hline 15 & 700 & $687 \pm 5$ & 50 & 7.7 & 6.1 & $2 \pm 1.0$ & $1 \pm 0.5$ & 14 & 600 & 0.68 \\
\hline
\end{tabular}

${ }^{a} 10 \%$ uncertainty in all values due to systematic uncertainty in mass flow controller calibrations. ${ }^{b}$ Fit first-order rate of MB sampling (see Section S1.5, ESI). ${ }^{c}$ Exponent in power law fit to the mass discrimination factor, $R=b(\mathrm{~m} / \mathrm{z})^{c}$ (see Section S1.4, ESI).

was one of the main motivations for this work. Finally, the product branching has negligible $P$-dependence as seen by comparing experiments \#7 and \#15, both of which were nominally conducted at $700 \mathrm{~K}$ but at different P's (10 and 50 Torr, respectively). Although the time-dependence of the product growth is slower at higher- $P$, that is likely due to slower radial diffusion impeding the transport of transient species to the MBMS sampling volume rather than a chemistry effect (Section S1.5, ESI $†$ ). Disregarding the time-dependence, both experiments \#7 and \#15 reach nearly identical steady-state product distributions, in agreement with the lack of $P$-dependence exhibited in the predictions of Fig. 2. The 25 Torr experiment (\#13) exhibits a behaviour intermediate to the 10 and 50 Torr experiments (Fig. S30-S32, ESI†). Fig. S32 and S36 in the ESI $†$ show that the instantaneous primary product ratios (relative to styrene/104 amu) at 25 and 50 Torr are essentially time-independent and in agreement with the model, further supporting the claim that the distinct time-dependence of the absolute signal at higher- $P$ is due to transport rather than chemistry effects.

Although there is great qualitative agreement between the measurements of Fig. 7 and the predictions of Fig. 2, there are some clear discrepancies. Most notably, at $600 \mathrm{~K}$ (experiment \#2) the largest product signals are at $m / z=118$ and $119 \mathrm{amu}$, nominally corresponding to p2-p4 and i1. The dominance of $119 \mathrm{amu}$ at later times is especially unexpected given its assumed identity as a radical. Clearly there is more going on than suggested by Fig. 2, and a more detailed model is needed, specifically, a model that includes not just the major reactions on the $\mathrm{C}_{9} \mathrm{H}_{11}$ PES, but also side and secondary reactions on other PESs, including those with the I atom. Ideally, transport effects should also be accounted for in the model, as well as the weighting of each species' signal by its PICS, the contribution of ${ }^{13} \mathrm{C}$ isotopologues and dissociative ionization (fragmentation). Such a model was developed (model predictions shown as thick solid lines in Fig. 7) and is described in the following section. Another purpose behind constructing a model for this flash photolysis system with MBMS detection is to test if the current theoretical understanding of $\mathrm{C}_{6} \mathrm{H}_{5}+\mathrm{C}_{3} \mathrm{H}_{6}$ is sufficient to quantitatively explain the experimental measurements. Of specific interest is whether the proposed aromatic-catalyzed 1,2-H-migration can really explain the 91 amu signal. After briefly describing the development of the model, its predictions will be compared in detail to each transient MBMS signal in order to test this understanding (next section).

Regarding the unexpected dominance of 118 and 119 amu at $600 \mathrm{~K}$, careful modelling (and a critical experiment) revealed that both $m / z$ 's are actually mostly attributable to fragments of i1-I. At higher T's, i1 undergoes unimolecular isomerization and decomposition reactions much faster compared to its reaction with the I atom, so the role of the I atom is largely diminished at $700 \mathrm{~K}$. At lower $T$ 's, the converse is true; hence MBMS experiments were not conducted below $600 \mathrm{~K}$.

Time-profiles for all 15 MBMS experiments (with model comparisons and commentary) are plotted in Fig. S9-S36 (ESI $\dagger$ ). It should be mentioned that for the experiments without $\mathrm{C}_{3} \mathrm{H}_{6}$, evidence of catalysis by the walls was observed. Specifically, fast hydrogenation of $\mathrm{C}_{6} \mathrm{H}_{5}$ to $\mathrm{C}_{6} \mathrm{H}_{6}$ was observed that was inexplicable by gas-phase chemistry (i.e., $\mathrm{C}_{6} \mathrm{H}_{5}$ self-reaction or reaction with the precursor). Slower, but still inexplicable, hydrogenation of the I atom to HI was also observed. For this reason, MBMS experiments were conducted at various $\left[\mathrm{C}_{3} \mathrm{H}_{6}\right]$ to confirm that sufficient $\mathrm{C}_{3} \mathrm{H}_{6}$ had been added such that $\mathrm{C}_{6} \mathrm{H}_{5}$ mostly reacted with $\mathrm{C}_{3} \mathrm{H}_{6}$ in the gas-phase, rather than abstracting an $\mathrm{H}$-atom from the wall.

\subsection{Modelling of flash photolysis with MBMS}

The overall approach to modelling the MBMS experiments is summarized in Fig. 9 and many of the individual steps are discussed in detail in the indicated ESI $\dagger$ sections. Briefly, after being "trained" on the relevant alkylaromatic chemistry, RMG was used to automatically construct a chemical mechanism for the important hydrocarbon (HC) chemistry occurring in the flash photolysis experiment. A separate sub-mechanism for I atom chemistry was manually created, largely taking inspiration 

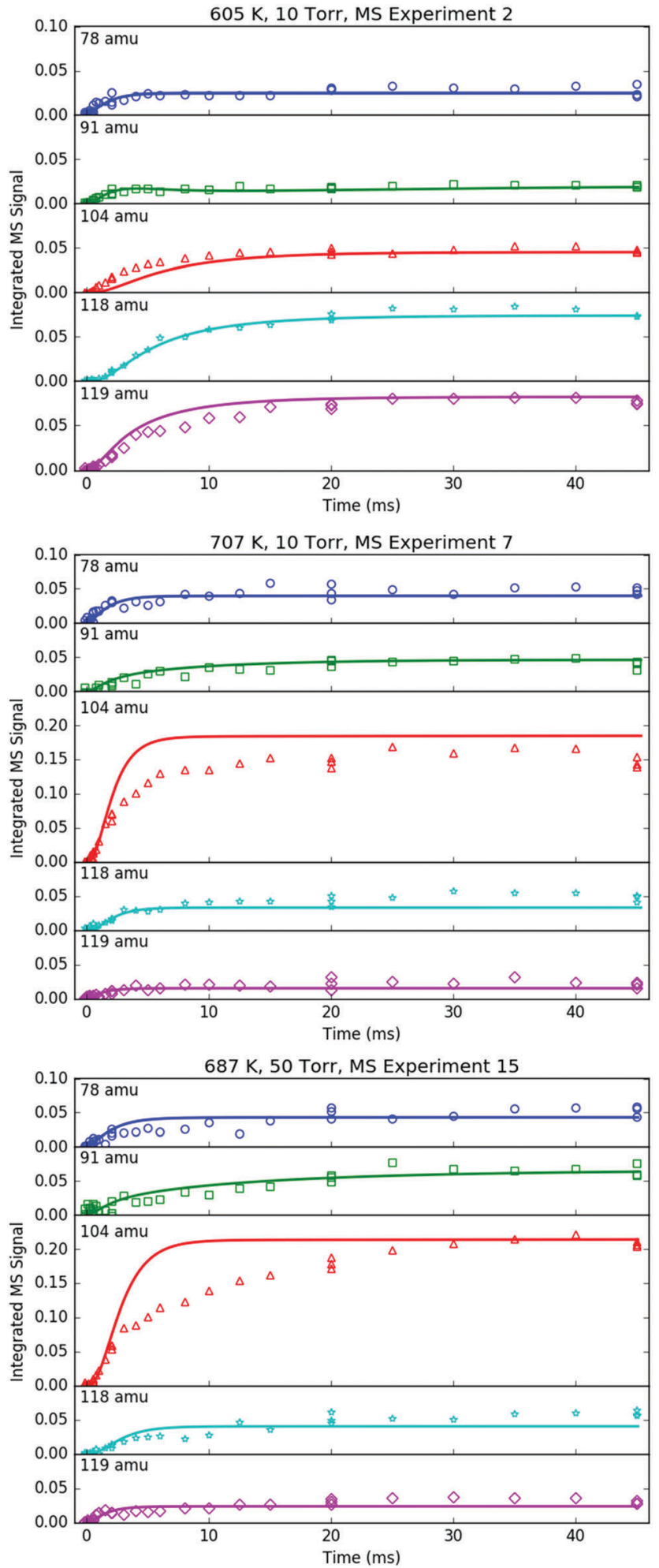

Fig. 7 Time profiles of primary phenyl radical + propene products measured with MBMS under indicated conditions. Markers are experimental measurements and lines are model results.

from recent work by Comandini et al. ${ }^{44}$ and Tranter et al. ${ }^{45}$ and combined with the HC mechanism. The main contribution of the I atom to the observed chemistry is as a recombination

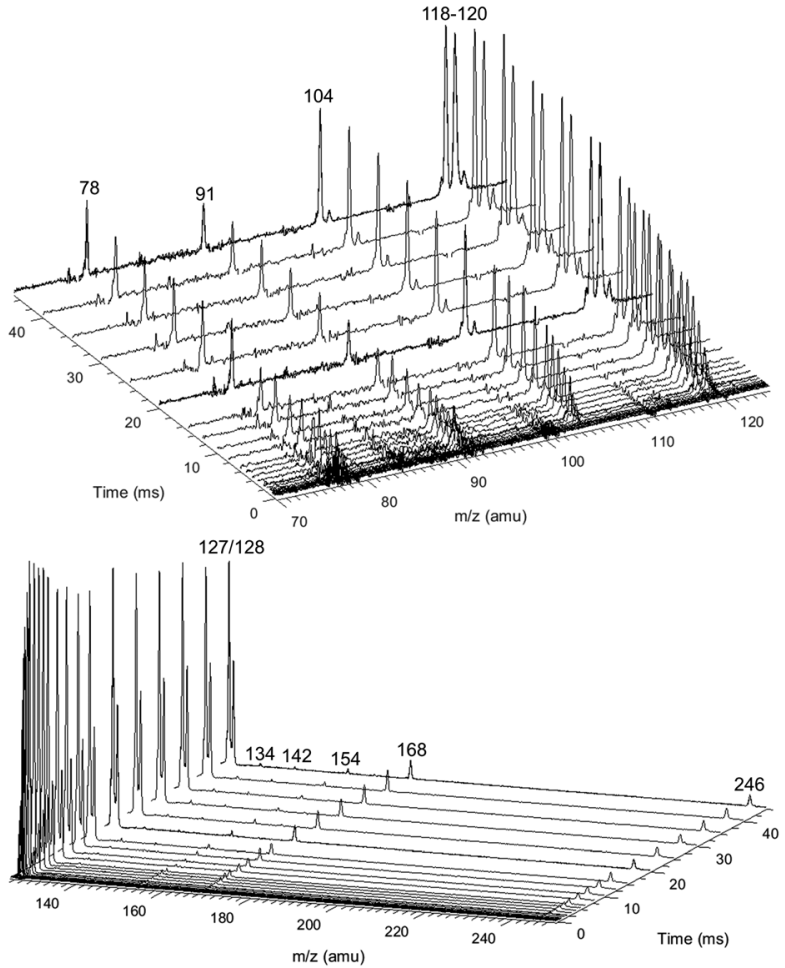

Fig. 8 Representative background-subtracted, time-resolved mass spectra at an $\mathrm{m} / \mathrm{z}$ range where primary phenyl radical + propene products appear (70-125 amu, top) and higher $\mathrm{m} / \mathrm{z}$ values where mostly the parent cations of iodide-containing species appear (125-250 amu, bottom). Measured at $605 \mathrm{~K}, 10$ Torr (experiment \#2). Only positive changes shown.

co-reactant: $\mathrm{R}+\mathrm{I}=\mathrm{R}-\mathrm{I}$, where $\mathrm{R}=\mathrm{H}, \mathrm{CH}_{3}, \mathrm{C}_{3} \mathrm{H}_{5}, \mathbf{p 1 0}$, i1 or another I. The initial radical concentration was fit to MBMS time-profiles of the photolytically produced I atom, and the combined $\mathrm{HC}+\mathrm{I}$ atom mechanism was simulated in an isothermal, isobaric batch reactor in order to obtain concentration profiles for each species i, $C_{\mathrm{i}}$. Each $C_{\mathrm{i}}$ is then weighted by the PICS for i, $\sigma_{\mathrm{PI}, \mathrm{i}}$, at $10.5 \mathrm{eV}$. PICS are mostly obtained from the literature, except for species where the literature values are unavailable, in which case either estimates or measurements of the PICS were made. The PICS weighted $C_{\mathrm{i}}$ profiles were converted to instantaneous MBMS signals by applying the mass discrimination factor, $R(\mathrm{~m} / \mathrm{z}) . R(\mathrm{~m} / \mathrm{z})$ was fit to the MBMS signals of internal standards, $S_{\text {int-std }}$, also present in the flash photolysis reactor during experiments at known, low concentrations. Transport effects were accounted for by a simple model adapted from Baeza-Romero et al. ${ }^{46}$ that lumps all of the time-smearing associated with MB sampling into a single first-order rate

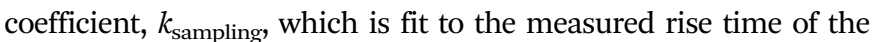
I atom MBMS profile. Once $S_{\mathrm{i} \text {,sampled }}$ profiles had been calculated, ${ }^{13} \mathrm{C}$ isotopologues of major species were created assuming a natural abundance of $1.1 \% \times \#$ of carbon atoms. Only isotopologues with zero or one ${ }^{13} \mathrm{C}$ are considered (or observed). Simulated species signals were then fragmented, again using either known, measured or estimated fragmentation patterns. Many of the iodide containing species, R-I, fragment extensively to $\mathrm{R}^{+}$due to the relatively weak $\mathrm{C}-\mathrm{I}$ bond, ${ }^{47}$ which was important 


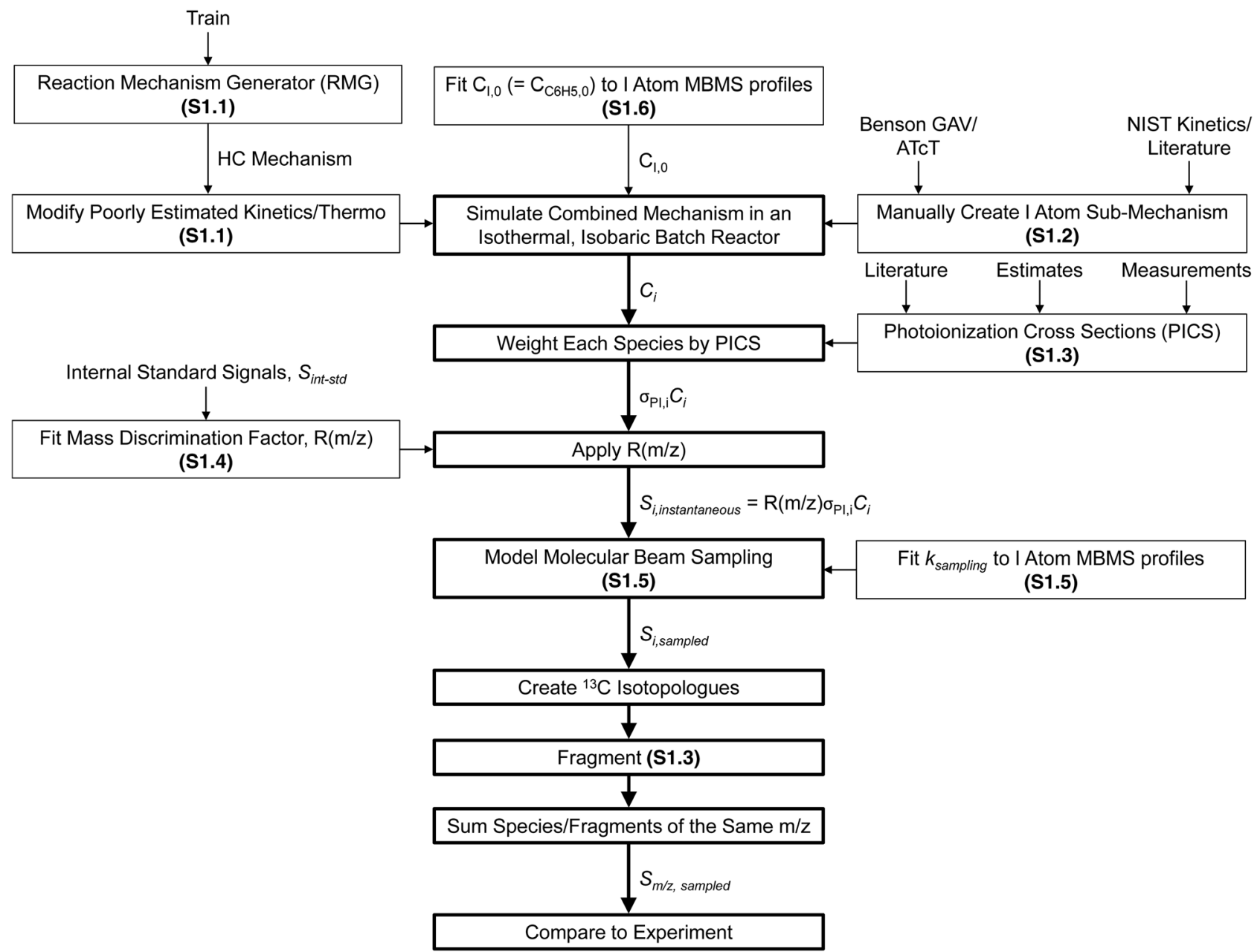

Fig. 9 Overall approach to modelling MBMS experiments. Specific ESI $\dagger$ sub-sections where certain aspects of the model are discussed in more detail are given in parentheses.

to take into account in the model. In particular, i1-I fragments to both $m / z=118$ and 119 amu $\left(\mathrm{C}_{9} \mathrm{H}_{10}{ }^{+}\right.$and $\left.\mathrm{C}_{9} \mathrm{H}_{11}{ }^{+}\right)$, and p10-I fragments to 91 amu $\left(\mathrm{C}_{7} \mathrm{H}_{7}{ }^{+}\right)$. Finally, species/fragments with the same $\mathrm{m} / \mathrm{z}$ were summed and the total, simulated MBMS

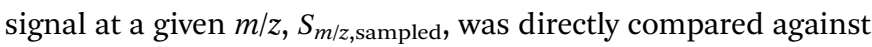
experiments.

Before delving into comparisons between the flash photolysis/MBMS model and experiments, it is helpful to summarize exactly what was fit to the $600 \mathrm{~K}$ MBMS data due to a lack of literature measurements:

(1) The rate of reactions between i1 and I atom (both recombination and disproportionations).

(2) The total PICS (10 Mb) and fragmentation pattern (1:1 at $m / z=91: 119 \mathrm{amu})$ of i1.

(3) The total PICS (80 Mb) and fragmentation pattern $(3: 6: 1$ at $m / z=118: 119: 248 \mathrm{amu})$ of i1-I.

Therefore, good agreement between the $600 \mathrm{~K}$ model and experiments is expected, especially for $m / z=118,119$ and $248 \mathrm{amu}$, which are all almost entirely attributable to i1-I. However, nothing was fit to the $700 \mathrm{~K}$ MBMS experiments, except for $k_{\text {sampling }}$ and $\mathrm{C}_{\mathrm{I}, 0}$, which had to be obtained from the I atom MBMS profiles. Therefore, the model should mostly be judged by its ability to simulate the $700 \mathrm{~K}$ experiments.

As already shown in Fig. 7, the model described in detail in Section S1 $(\mathrm{ESI} \dagger)$ matches the primary product profiles at 10 Torr and both 600 and $700 \mathrm{~K}$. At 50 Torr and $700 \mathrm{~K}$, although the simulated $t$-dependence is too fast because of inhibited diffusion as discussed in Section S1.5 (ESI $\dagger$ ), the final product distribution (and instantaneous product ratios in the ESI $\dagger$ ) still matches the model well. This section will focus on comparing every individual $\mathrm{m} / \mathrm{z}$ with measured time-dependence against the model for both 600 and $700 \mathrm{~K}$ (10 Torr only), starting with the five primary products $(\mathrm{m} / z=78,91,104,118$ and $119 \mathrm{amu})$. Identical comparison plots are made for all of the MBMS experiments in Fig. S9-S36 (ESI $\dagger$ ).

78 and 104 amu are compared together in Fig. 10 because they both are unique in being the only major product signals entirely attributable to just one species: $\mathrm{C}_{6} \mathrm{H}_{6}$ and $\mathbf{p} \mathbf{1}$ (styrene), respectively. As such, the 78:104 ratio is indicative of the competition between $\mathrm{H}$-abstraction and radical addition in the reaction of $\mathrm{C}_{6} \mathrm{H}_{5}$ with $\mathrm{C}_{3} \mathrm{H}_{6}$, and the model could be fit to the measurements by adjusting the relative barrier heights of 

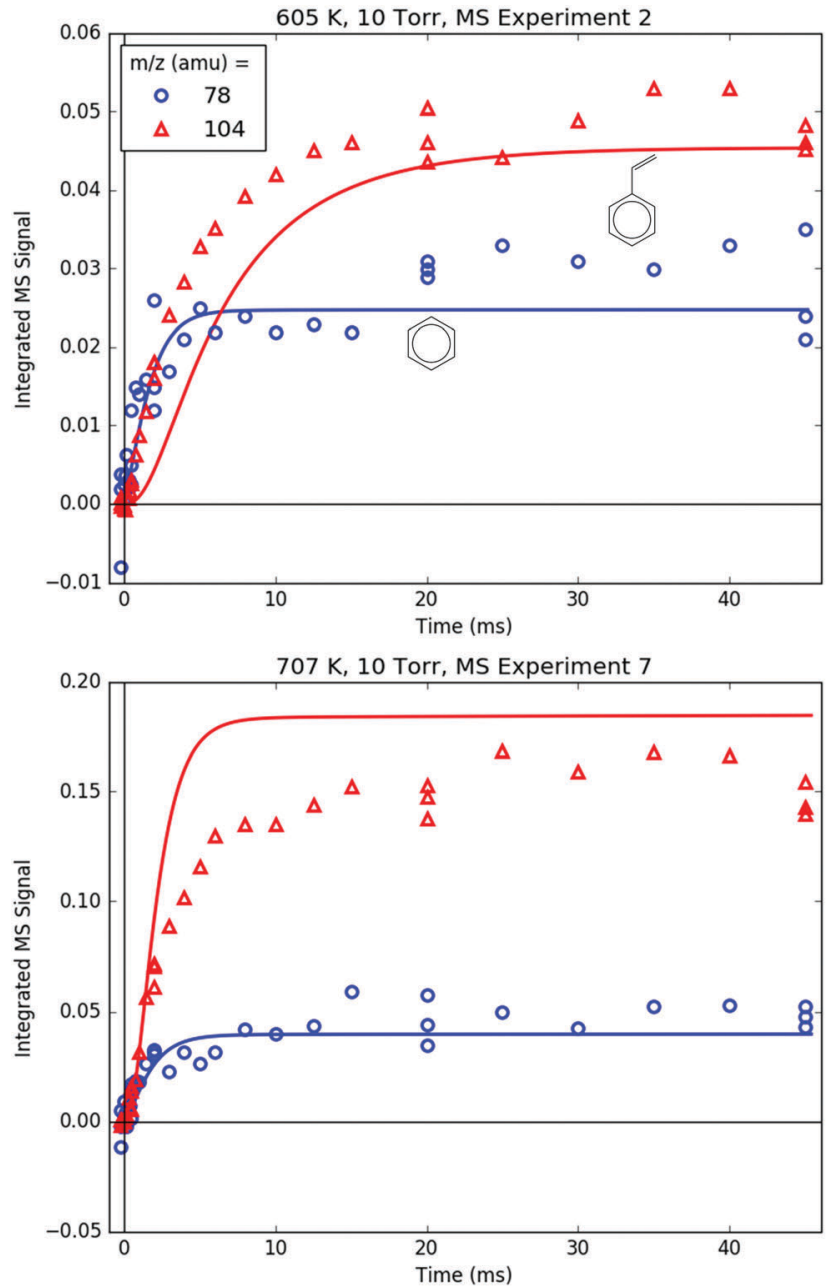

Fig. 10 Measured (markers) and modelled (thick lines) 78 and 104 amu MBMS signals under indicated conditions. These are the only two primary phenyl radical + propene product $\mathrm{m} / \mathrm{z}$ 's that are entirely attributable to one species: benzene and styrene, respectively.

those two entrance channels. However, the measurements and the simulations already overlap considering the uncertainty in the model (at least $\pm 15 \%$ due to the PICS). Therefore it was deemed unnecessary (and essentially meaningless) to fit the barrier heights. Also, at $600 \mathrm{~K}$, both the model and the experiment show a slower growth time scale for $104 \mathrm{amu}(\sim 10 \mathrm{~ms})$, which is formed in two steps $\left(\mathrm{C}_{6} \mathrm{H}_{5}+\mathrm{C}_{3} \mathrm{H}_{6} \rightarrow \mathbf{i} \mathbf{1} \rightarrow \mathbf{p} \mathbf{1}+\mathrm{CH}_{3}\right)$, compared to $78 \mathrm{amu}(\sim 1 \mathrm{~ms})$, which is formed in only one step $\left(\mathrm{C}_{6} \mathrm{H}_{5}+\right.$ $\left.\mathrm{C}_{3} \mathrm{H}_{6} \rightarrow \mathrm{C}_{6} \mathrm{H}_{6}+\mathrm{C}_{3} \mathrm{H}_{5}\right)$. This demonstrates that although the time resolution of the current MBMS experiments is only $\sim 1 \mathrm{~ms}$, important differences in chemical time-scales can still be resolved.

$91 \mathrm{amu}$, shown in Fig. 11, is modelled as a complicated mixture of three different species signals all with distinct $t$ - and $T$-dependence: p10 (benzyl radical) and fragments of both i1 and p10-I. For $600 \mathrm{~K}$, the agreement at early times is due to fitting the extent of i1 fragmentation to $91 \mathrm{amu}$. The measurements at later time were not fit, however, and are in excellent agreement with the model, which mostly consists of the p10-I contribution.
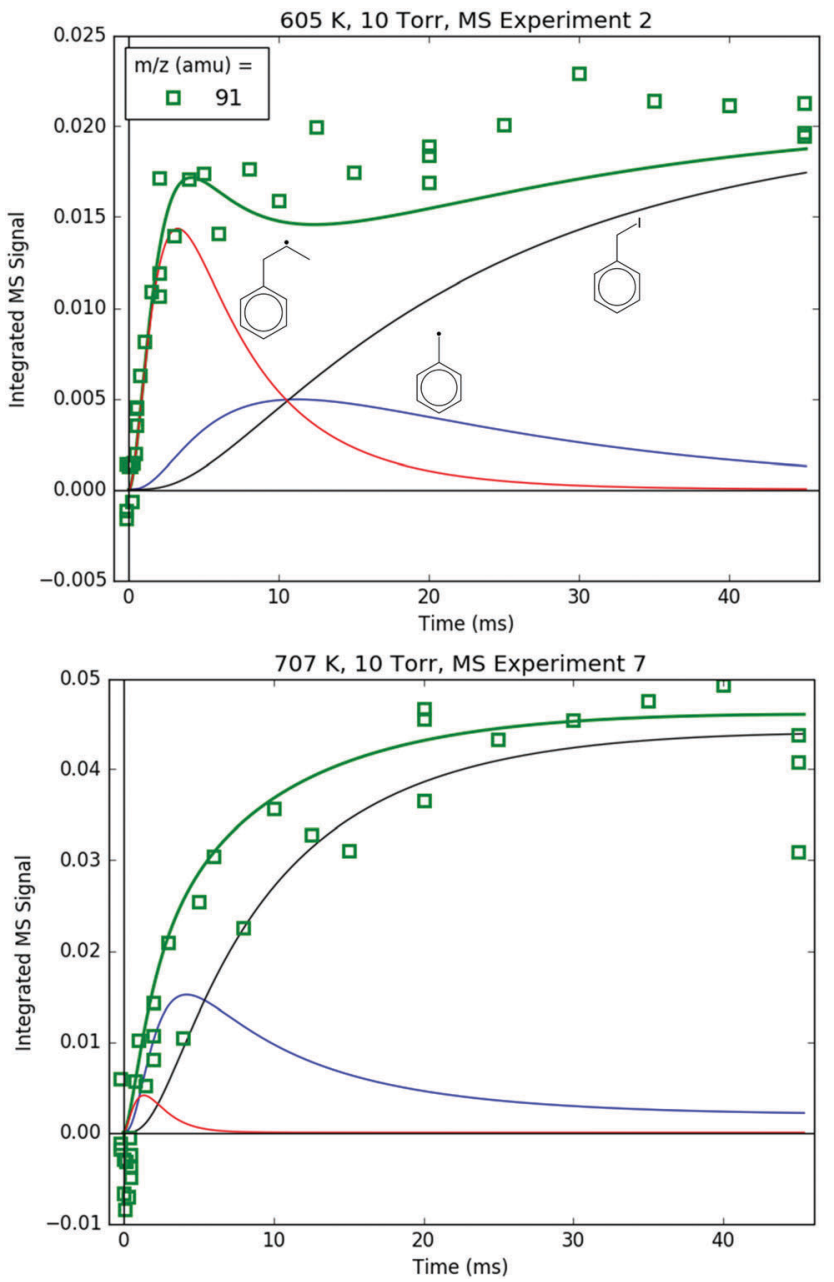

Fig. 11 Measured (markers) and modelled (thick lines) 91 amu MBMS signal under indicated conditions. The thin lines correspond to different species contributing to the overall modelled 91 amu signal: the $\mathrm{C}_{7} \mathrm{H}_{7}{ }^{+}$ fragments of $\mathbf{i}$ (red) and benzyl iodide (black), and the parent cation of the benzyl radical (blue)

Even more remarkable is that the model still performs well at $700 \mathrm{~K}$, where nothing was fit, and the contribution of i1 is greatly diminished because of its fast unimolecular isomerization/ decomposition at that $T$. Once again, at later times the model is dominated by p10-I, in accordance with the experiment. The measurements in Fig. 11 and the ability of the model to quantitatively explain them provide strong support for the never-before-seen aromatic-catalyzed 1,2-H-migration proposed in Section 4.1. Without the addition of this pathway to Kislov et al.'s original PES, ${ }^{11}$ virtually no $\mathbf{p 1 0}$ or $\mathbf{p 1 0}$-I would be predicted, and the long-time 91 amu signal observed experimentally would be unaccounted for.

Both 118 and 119 amu, shown in Fig. 12 and 13, respectively, have large contributions from fragmentation of i1-I. $119 \mathrm{amu}$ in particular is dominated by i1-I in the simulations at both 600 and $700 \mathrm{~K}$, with a negligible contribution from the parent cation of i1. $118 \mathrm{amu}$ exhibits a more diverse mix of simulated species: at $600 \mathrm{~K}$ i1-I is the largest contributor to the $118 \mathrm{amu}$ signal, but the phenylpropene isomers $\mathbf{p} 2$ and $\mathbf{p} 3$ also make a 

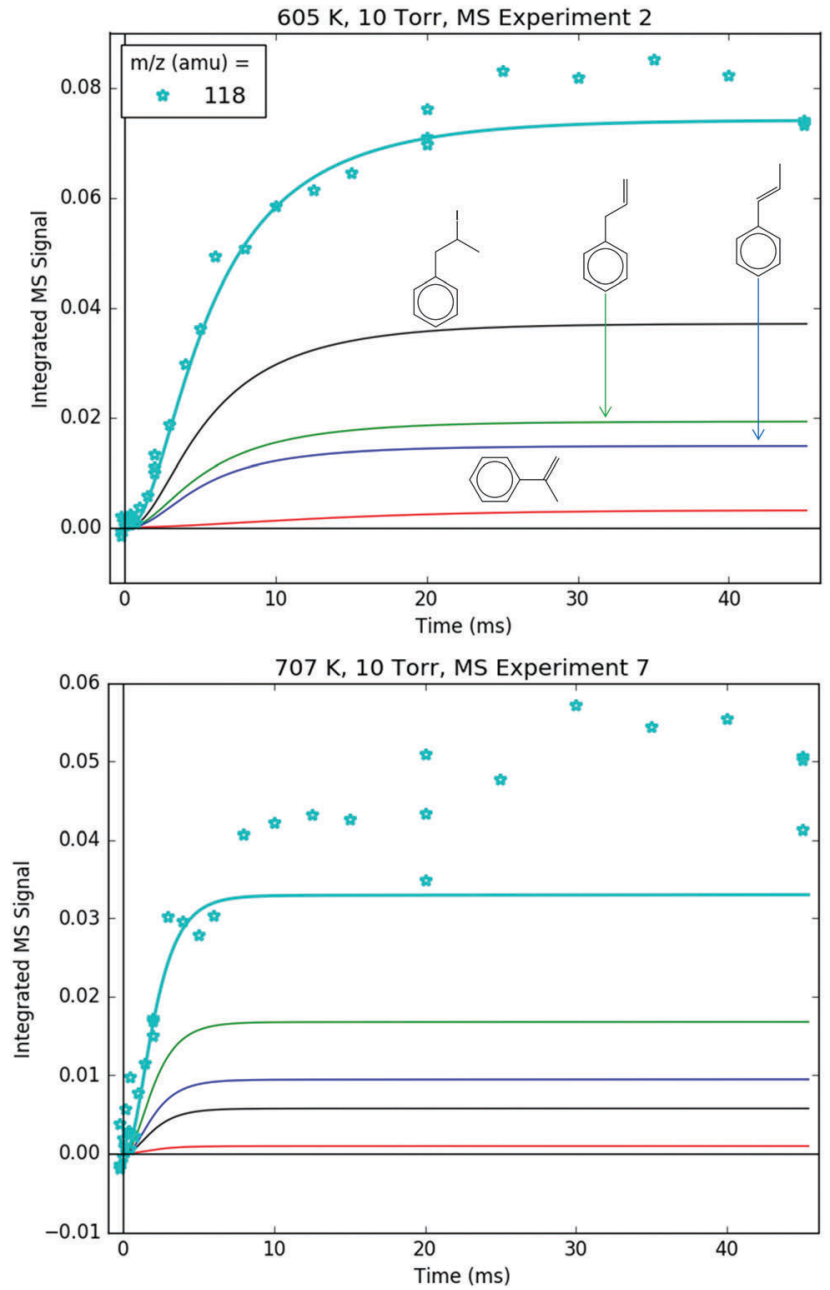

Fig. 12 Measured (markers) and modelled (thick lines) 118 amu MBMS signal under indicated conditions. The thin lines correspond to different species contributing to the overall modelled 118 amu signal: the $\mathrm{C}_{9} \mathrm{H}_{10}{ }^{+}$ fragment of i1-I (black) and the parent cations of 1-, 2- and 3-phenylpropene (blue, red and green, respectively).

noticeable contribution. At $700 \mathrm{~K}$, the roles are switched: p2 and $\mathbf{p} \mathbf{3}$ are dominant over i1-I. This is because i1 is undergoing unimolecular reactions too quickly at higher $T$ to participate in bimolecular recombination with the I atom, and hence the importance of i1-I is diminished at $700 \mathrm{~K}$. It is important to reiterate that the good agreement at $600 \mathrm{~K}$ between the model and the experiments at 118 and 119 amu (and 246 amu shown later) is due to fitting of the unknown PICS and fragmentation pattern of i1-I. However, the fact that the same PICS and fragmentation pattern are used in the model at $700 \mathrm{~K}$ with satisfactory results gives credibility to the model.

Overall, all five of the primary $\mathrm{C}_{6} \mathrm{H}_{5}+\mathrm{C}_{3} \mathrm{H}_{6}$ product $m / z$ 's are well-described by the model, imparting greater confidence to the predictions of Section 4.1 upon which the model is based, and encouraging the extension of those predictions to analogous systems (Section 4.6). The remainder of this section will compare the model simulations to the MBMS experiments for all of the other transient $m / z^{\prime}$ s.
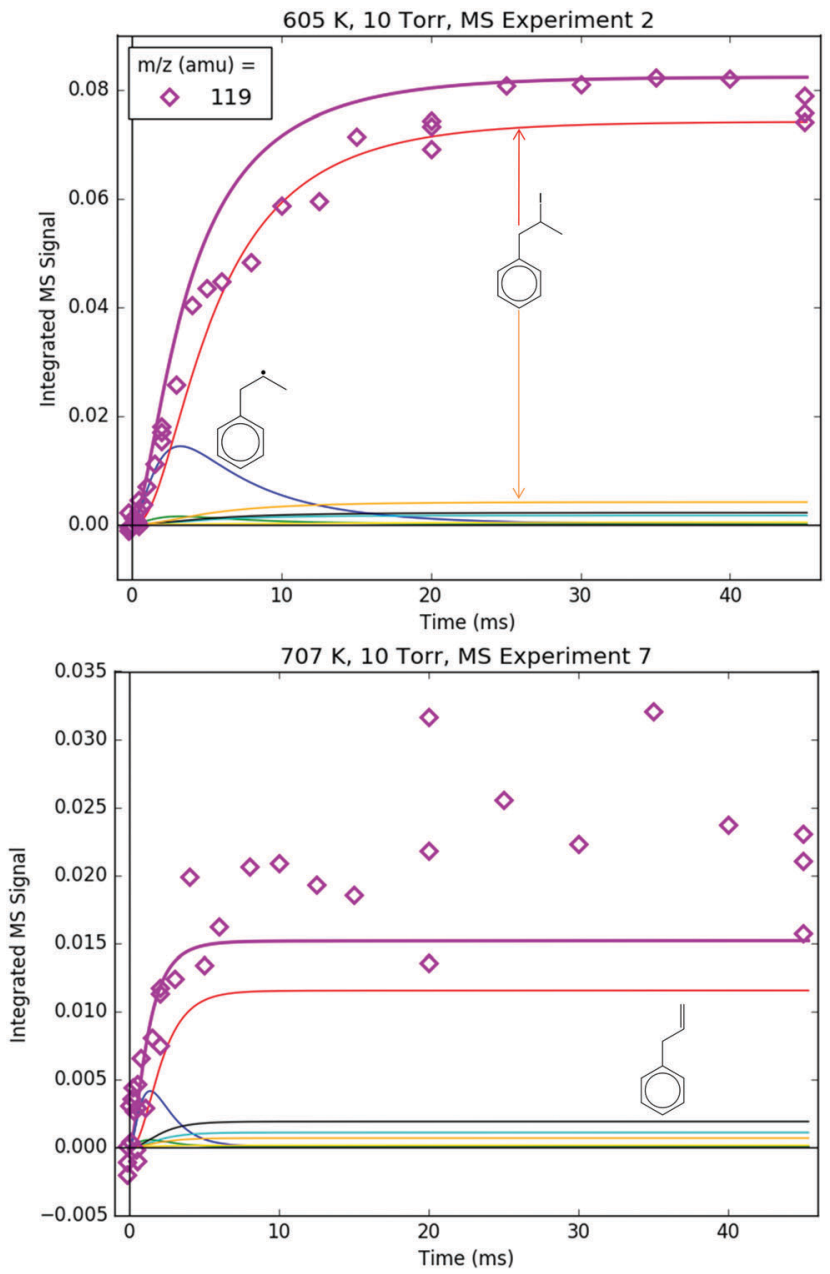

Fig. 13 Measured (markers) and modelled (thick lines) 119 amu MBMS signal under indicated conditions. The thin lines correspond to different species contributing to the overall modelled 119 amu signal: the parent cations of i1 and i2 (blue and green, respectively), the $\mathrm{C}_{9} \mathrm{H}_{11}{ }^{+}$and ${ }^{13} \mathrm{C}$-containing $\mathrm{C}_{9} \mathrm{H}_{10}{ }^{+}$fragments of i1-I (red and orange, respectively) and the parent cations of ${ }^{13} \mathrm{C}$-containing 1-, 2- and 3-phenylpropene (cyan, gold and black, respectively).

Fig. 14 compares the I atom and $\mathrm{HI}$ at 127 and $128 \mathrm{amu}$, respectively. The rise time of the $127 \mathrm{amu}$ signal was fit for $k_{\text {sampling, }}$, and its absolute value was roughly fit for $[\mathrm{I}]_{0}$. Therefore, the agreement between the modelled and measured I atom at early times is unremarkable. At longer times, however, the simulated decay of the I atom was not fit and generally follows the trend of the measured 127 amu signal, especially considering that the I atom PICS is $\sim 35 \%$ uncertain (Table S3, ESI $\dagger$ ). Given the importance of i1 recombination with the I atom at $600 \mathrm{~K}$ in explaining many of the observations made at that $T$, it is reassuring that the absolute I atom signal itself is also described well by the model over the entire measured time range.

As discussed in Section S1.2 (ESI $\dagger$ ), HI is mostly formed through wall catalysis, which was not included in the model. Therefore, $\mathrm{HI}$ is underpredicted, especially at $600 \mathrm{~K}$. At $700 \mathrm{~K}$, the wall catalysis effect is reduced, probably because of less 

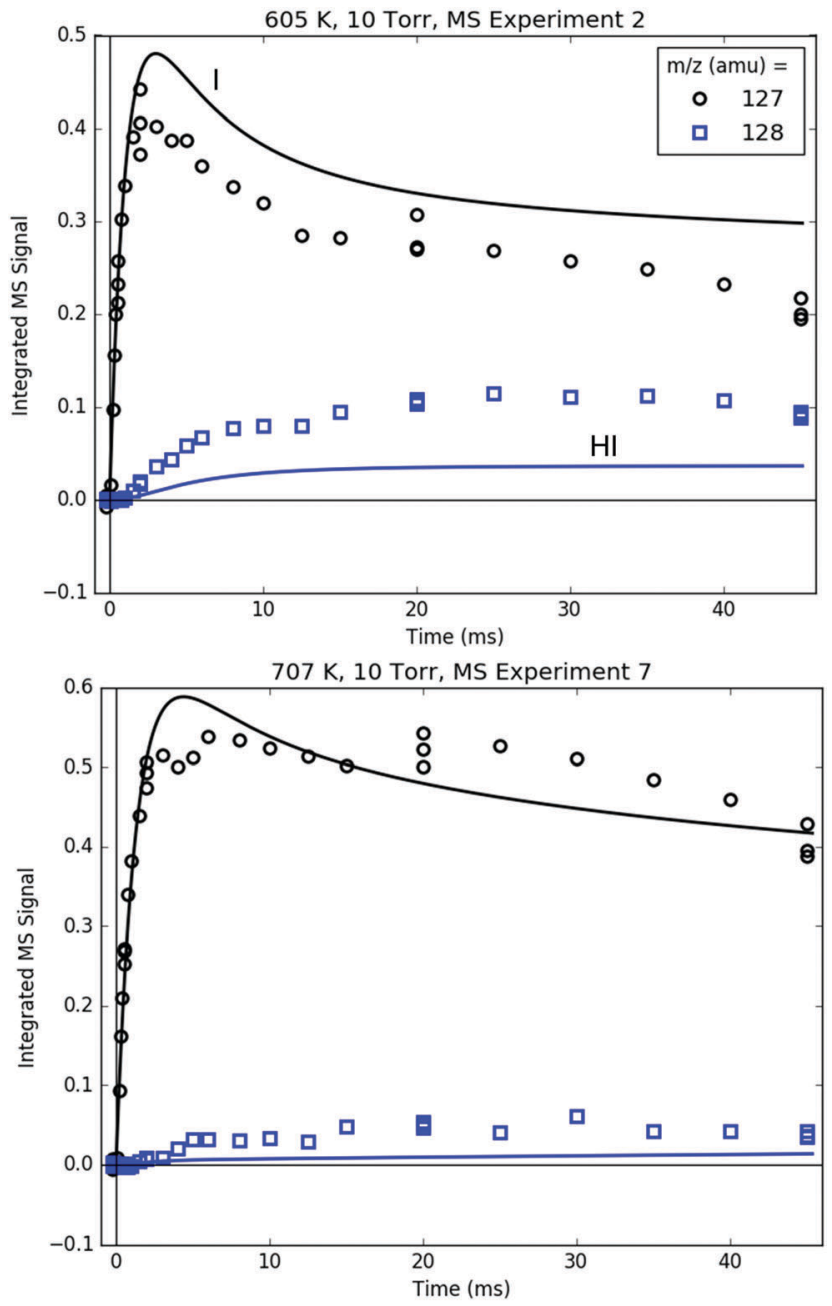

Fig. 14 Measured (markers) and modelled (thick lines) 127 (black) and 128 (blue) amu MBMS signals under indicated conditions, which are exclusively attributable to I and $\mathrm{HI}$.

adsorption on the wall at higher $T,^{48}$ but $\mathrm{HI}$ is still underpredicted. Nonetheless, matching $\mathrm{HI}$ is not critical to the main goals and conclusions of this work, and is not discussed further.

Fig. 15 compares the $\mathrm{C}_{6} \mathrm{H}_{5}$ signal measured both by MBMS at $77 \mathrm{amu}$ and by simultaneously recorded $505.3 \mathrm{~nm}$ absorbance. As a short-lived species, $\mathrm{C}_{6} \mathrm{H}_{5}$ is difficult to resolve with MBMS, an issue that is compounded by the overlap of $77 \mathrm{amu}$ with a fragment of $\mathrm{C}_{6} \mathrm{H}_{5} \mathrm{I}$, which is present in relatively high concentration. However, the decay of $\mathrm{C}_{6} \mathrm{H}_{5}$ was clearly resolved by $505.3 \mathrm{~nm}$ absorbance, which is a much faster and non-intrusive detection technique for measuring overall kinetics. The simulated $\mathrm{C}_{6} \mathrm{H}_{5}$ decay (without sampling effects, of course) is in good agreement with the $505.3 \mathrm{~nm}$ absorbance, which is expected given that the terminal addition rate of $\mathrm{C}_{6} \mathrm{H}_{5}+\mathrm{C}_{3} \mathrm{H}_{6}$ was previously fit to absorbance measurements in Section 4.2. Fig. 15 and Fig. 9-13 illustrate the complementary nature of laser absorbance coupled with MBMS for kinetic studies: laser absorbance can resolve the time dependence of only one species (or at most a few species if there is spectral overlap that can be deconvoluted) with high $t$-resolution, whereas
MBMS can resolve the time dependence of many species with lower $t$-resolution. Of course, the $t$-resolution of the MBMS measurements reported here can and should be improved in the future, but MBMS is unlikely to supplant laser absorbance as the preferred method for overall kinetics quantification for multiple reasons to be discussed in an upcoming publication. ${ }^{17}$

Biphenyl, $\mathrm{C}_{6} \mathrm{H}_{5}-\mathrm{C}_{6} \mathrm{H}_{5}$, is also measured with MBMS at $154 \mathrm{amu}$ (Fig. 15), and the model is in near-quantitative agreement, especially considering that the PICS of $\mathrm{C}_{6} \mathrm{H}_{5}-\mathrm{C}_{6} \mathrm{H}_{5}$ was estimated by the method of Bobeldijk et al. ${ }^{49}$ The $\mathrm{C}_{6} \mathrm{H}_{5}$ self-recombination rate $\left(\mathrm{C}_{6} \mathrm{H}_{5}+\mathrm{C}_{6} \mathrm{H}_{5} \rightarrow \mathrm{C}_{6} \mathrm{H}_{5}-\mathrm{C}_{6} \mathrm{H}_{5}\right)$ used in the model is also an unadjusted estimate used directly from RMG.

Measured and modelled $\mathrm{m} / \mathrm{z}$ signals corresponding to the products of i1 bimolecular recombination with the $\mathrm{H}$ atom $(120 \mathrm{amu}), \mathrm{CH}_{3}(134 \mathrm{amu})$ and $\mathrm{C}_{3} \mathrm{H}_{5}(160 \mathrm{amu})$ are shown in Fig. 16 and 17. At $600 \mathrm{~K}$, the signal at $m / z=120 \mathrm{amu}$ is actually mostly attributable to the ${ }^{13} \mathrm{C}$ isotopologues of various $119 \mathrm{amu}$ species/fragments (specifically, the fragment of i1-I), with propylbenzene (from i1 adding an $\mathrm{H}$ either by recombination, $\mathrm{H}$-abstraction or disproportionation) contributing $\sim 1 / 3$ of the total modelled signal. At $700 \mathrm{~K}$, the simulated signal is about an order of magnitude lower, below the detection limit of the MBMS, consistent with the lack of any measurable $120 \mathrm{amu}$ signal. 134 and 160 amu are entirely attributable to the expected species: i1- $\mathrm{CH}_{3}$ and i1- $\mathrm{C}_{3} \mathrm{H}_{5}$. At $600 \mathrm{~K}$, the signal is discernible but near the detection limit, and by $700 \mathrm{~K}$ the simulated and measured signals have dropped below the detection limit. As mentioned before in a different context, this is because i1 is too short-lived at higher $T$ 's to undergo bimolecular reactions (such as recombination with $\mathrm{I}, \mathrm{CH}_{3}$ or $\mathrm{C}_{3} \mathrm{H}_{5}$ ). Although not shown, in the model another secondary product of i1 bimolecular reaction, i1-dimer, has a similar predicted signal and $T$-dependence as the species in Fig. 16. However, no transient signal at the corresponding parent $\mathrm{m} / \mathrm{z}(238 \mathrm{amu})$ was observed even at $600 \mathrm{~K}$ (Fig. 8). Given that the PICS of i1-dimer was estimated as $2 \times$ the PICS of propylbenzene $(2 \times 30=60 \mathrm{MB}),{ }^{49}$ its signal is probably slightly overpredicted, which being so close to the detection limit can make the difference between seeing it and not seeing it experimentally.

Finally, Fig. 18 shows the parent $m / z^{\prime}$ s of all of the important iodide-containing species: $142 \mathrm{amu}$ for $\mathrm{CH}_{3} \mathrm{I}, 168 \mathrm{amu}$ for $\mathrm{C}_{3} \mathrm{H}_{5} \mathrm{I}$ and $246 \mathrm{amu}$ for i1-I. The parent $m / z$ signal for p10-I at $218 \mathrm{amu}$ is below the detection limit due to its severe $(\sim 10: 1)^{50}$ fragmentation to $\mathrm{C}_{7} \mathrm{H}_{7}^{+}$. The modelled $\mathrm{C}_{3} \mathrm{H}_{5} \mathrm{I}$ and i1-I both quantitatively match their respective $\mathrm{m} / z$ signal measurements at both T's (keeping in mind that the PICS and fragmentation pattern of i1-I were fit to the $600 \mathrm{~K}$ experiments). $\mathrm{CH}_{3} \mathrm{I}$, however, is overpredicted, especially at $700 \mathrm{~K}$. As discussed in Section S1.2 (ESI $\dagger$ ), this is probably due to fall-off effects, not included in the I atom sub-mechanism, lowering the effective rate of $\mathrm{CH}_{3}+\mathrm{I} \rightarrow \mathrm{CH}_{3} \mathrm{I}$ at higher T's and lower $P$ 's than where the original rate measurement was conducted $\left(400 \mathrm{~K}, 82\right.$ Torr $\left.\mathrm{CH}_{3} \mathrm{I}\right) .{ }^{51}$ Although the $\mathrm{CH}_{3}+\mathrm{I} \rightarrow \mathrm{CH}_{3} \mathrm{I}$ rate could be fit to match the $142 \mathrm{amu}$ MBMS signal, given the uncertainties in the many other $\mathrm{CH}_{3}$ reactions and given that $\mathrm{CH}_{3}$ was not observed with 

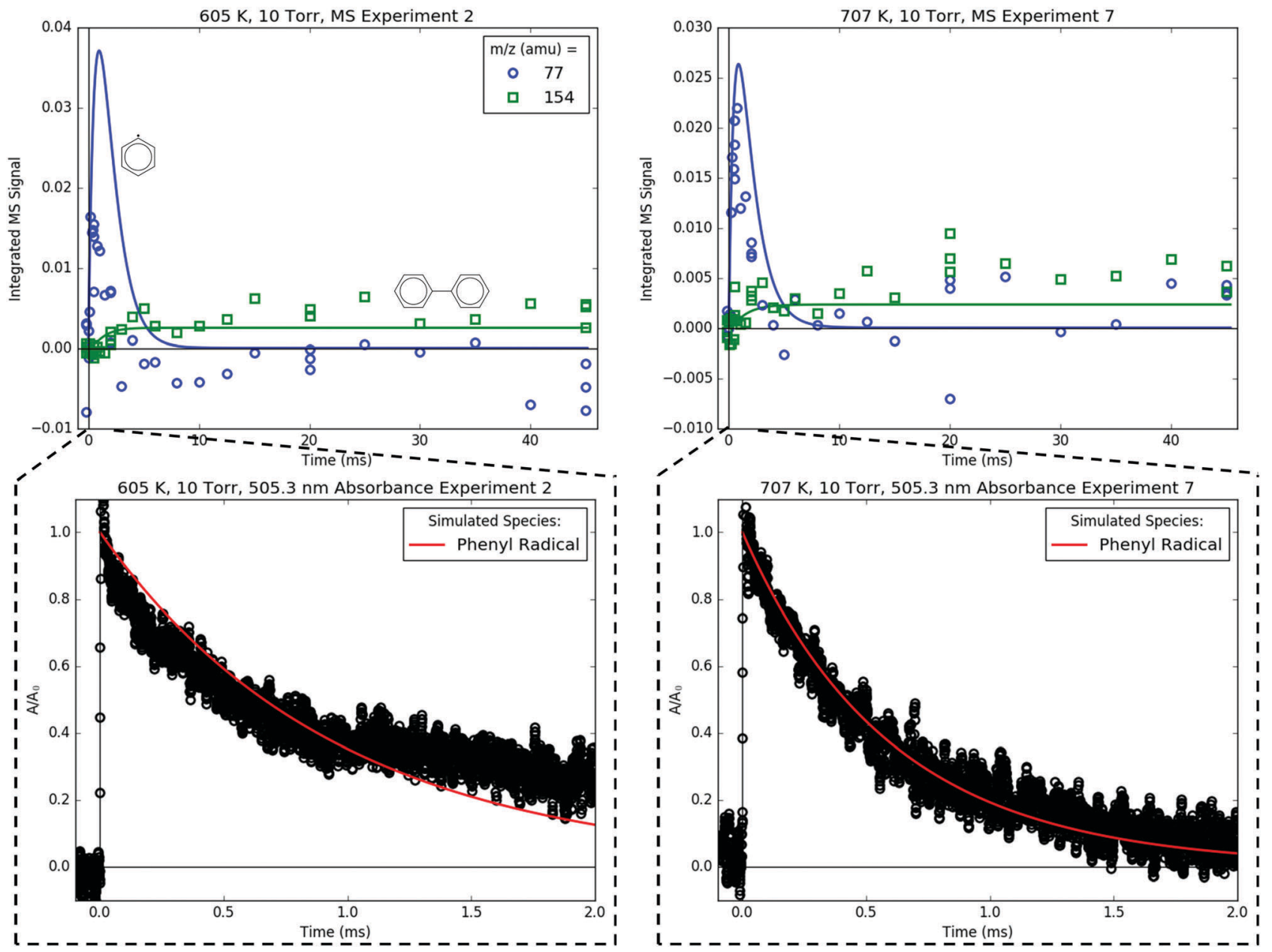

Fig. 15 Top: Measured (markers) and modelled (lines) 77 (blue) and 154 (green) amu MBMS signals under indicated conditions, which are exclusively attributable to the phenyl radical and biphenyl. Bottom: Measured (markers) and modelled (red line) $505.3 \mathrm{~nm}$ absorbance traces recorded simultaneously as MBMS plots on top.

MBMS (discussed in the following paragraph), it was decided that there were too many variables for too little data, and the adjustment of one variable would have no physical significance.

Of equal importance as what was observed is what should have been observed but wasn't. Specifically, the model predicted significant concentrations of $\mathrm{CH}_{3}$, methane $\left(\mathrm{CH}_{4}\right.$, from $\mathrm{H}$-abstraction by $\left.\mathrm{CH}_{3}\right), \mathrm{C}_{2} \mathrm{H}_{4}$ (co-product of p10), ethane $\left(\mathrm{C}_{2} \mathrm{H}_{6}\right.$, from self-recombination of $\left.\mathrm{CH}_{3}\right)$ and $\mathrm{C}_{3} \mathrm{H}_{5}$ (co-product of $\mathrm{C}_{6} \mathrm{H}_{6}$ and general product of $\mathrm{H}$-abstraction from $\mathrm{C}_{3} \mathrm{H}_{6}$ ), none of which were observed experimentally by MBMS. There are three explanations for the lack of MBMS signal for these species:

(1) The species ionization energy is $>10.5 \mathrm{eV}$, as in the case of $\mathrm{CH}_{4}\left(12.6 \mathrm{eV}^{52}\right), \mathrm{C}_{2} \mathrm{H}_{4}\left(10.51 \mathrm{eV}^{53}\right)$ and $\mathrm{C}_{2} \mathrm{H}_{6}\left(11.5 \mathrm{eV}^{54}\right)$.

(2) Although the simulated species concentration is high, once PICS and $R(\mathrm{~m} / \mathrm{z})$ are taken into account the simulated signal is below the MBMS detection limit, as in the case of $\mathrm{CH}_{3}$ at $600 \mathrm{~K}\left(\mathrm{CH}_{3}\right.$ has a relatively small PICS and as a light species it is disfavoured by $R(\mathrm{~m} / \mathrm{z})$ ).

(3) The time-dependent species signal overlaps with some large time-independent signal, as in the case of $\mathrm{CH}_{3}$ and $\mathrm{C}_{3} \mathrm{H}_{5}$, both of which overlap with a large $\mathrm{C}_{3} \mathrm{H}_{6}$-fragment.
As the co-product of $\mathbf{p} \mathbf{1}$, which is clearly observed as a dominant product at $700 \mathrm{~K}, \mathrm{CH}_{3}$ is the most glaringly absent signal in the MBMS. Besides the second and third experimental explanations above, the disparity between modelled and non-existent measured $\mathrm{CH}_{3}$ could certainly be due to the model. Specifically, the model is overpredicting the concentration of $\mathrm{CH}_{3}$ (Fig. S8, ESI $\dagger$ ) because, as discussed in Section S1.1 (ESI $\dagger$ ), there is no $k_{\text {wall }}$ for $\mathrm{CH}_{3}$.

To conclude this lengthy section on quantitatively modelling the MBMS experiments, the intention of building a detailed model following the approach of Fig. 9 was not to "perfectly" match experiments. Given the 100s of parameters in this model including rate coefficients, thermochemical parameters, PICS, $k_{\text {sampling }}$ and $C_{\mathrm{I}, 0}$, the relatively small experimental data set reported here (15 different conditions) could easily be fit perfectly and automatically. Rather, the goal was to build a model independent of the experiments that could quantitatively explain all of the major observations, using reasonable estimates. The model presented above has achieved this goal, and in the process has provided quantitative support for the predictions of Section 4.1, which can now be confidently extended to other alkylaromatic systems using RMG (Section 4.6). 

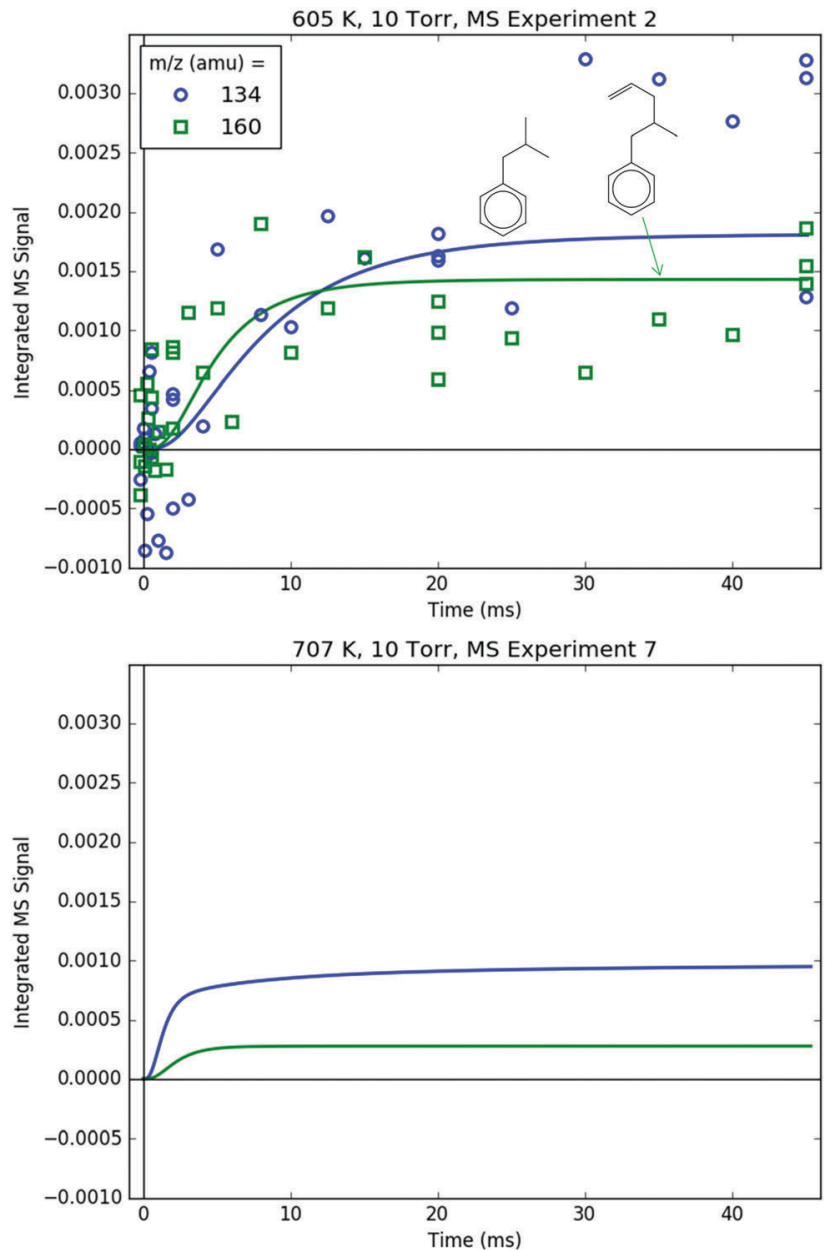

Fig. 16 Measured (markers) and modelled (thick lines) 134 (blue) and 160 (green) amu MBMS signals under indicated conditions. Both signals are exclusively attributed to the products of i1 recombination with other radicals: methyl and allyl radical, respectively. Both signals were too low to be detected at $707 \mathrm{~K}$, therefore only the modelled signal is shown under that condition.

\subsection{Products measured by absorbance}

Attempts were also made to quantify product branching by laser absorbance given that at room temperature three of the important radicals in the $\mathrm{C}_{6} \mathrm{H}_{5}+\mathrm{C}_{3} \mathrm{H}_{6}$ system, $\mathrm{C}_{6} \mathrm{H}_{5}, \mathrm{C}_{3} \mathrm{H}_{5}$ and p10, are known to exhibit distinct visible absorbance features at $504.8,{ }^{14} 408.4^{37}$ and $447.7 \mathrm{~nm},{ }^{38}$ respectively (Fig. 19). However, the strength of these features is expected to drop with increasing $T$ due to line-broadening. ${ }^{16}$ In particular, the peak absorbance cross section for p10 at $447.7 \mathrm{~nm}$ is known to sharply decrease by $\sim 1$ order of magnitude when increasing $T$ from 300 to $600 \mathrm{~K},{ }^{55}$ such that at $T \geq 600 \mathrm{~K}$ all three radicals in Fig. 19 will have similar absorbance cross sections of $\sim 2 \times 10^{-19} \mathrm{~cm}^{2}$.

Table S4 (ESI $\dagger$ ) summarizes the conditions of the experiments to probe for products $\left(\mathrm{C}_{3} \mathrm{H}_{5}\right.$ and p10) with laser absorbance. The experiment \#'s are a continuation of those for the MBMS experiments. Experiments \#2-4, 16-18 and 22-24 were conducted under nearly identical conditions (nominally $600 \mathrm{~K}$, 10 Torr and a range of $\left[\mathrm{C}_{3} \mathrm{H}_{6}\right]$, the radical concentration was
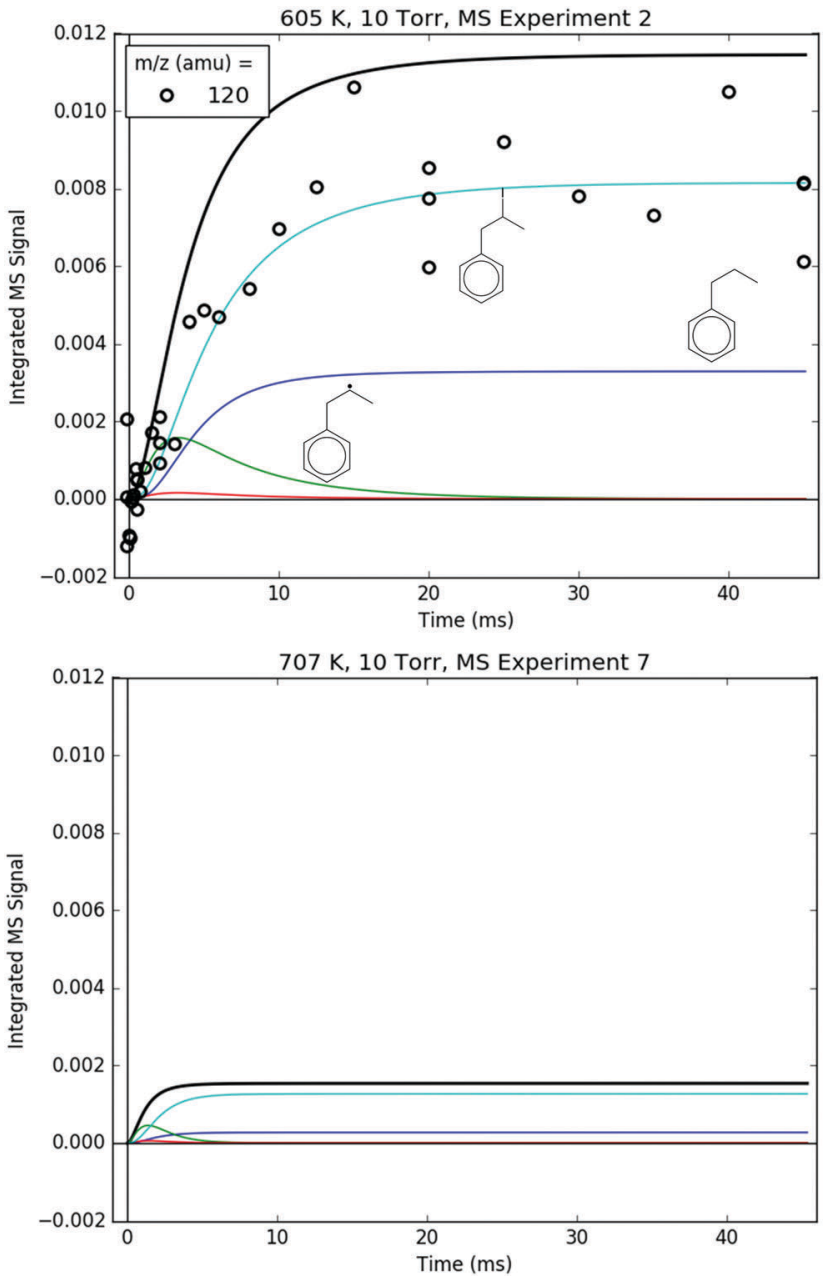

Fig. 17 Measured (markers) and modelled (thick lines) 120 amu MBMS signal under indicated conditions. The thin lines correspond to different species contributing to the overall modelled 120 amu signal: the parent cation of propylbenzene (blue), the ${ }^{13} \mathrm{C}$-containing $\mathrm{C}_{9} \mathrm{H}_{11}{ }^{+}$fragment of i1-I (cyan) and the parent cations of ${ }^{13} \mathrm{C}$-containing i1 and i2 (green and red, respectively). The overall $120 \mathrm{amu}$ signal at $707 \mathrm{~K}$ was too low to be detected, therefore only the modelled signal is shown under that condition.

slightly higher for the product probing experiments) but the probe laser wavelength was varied from 505.3, 404.8 and $447.7 \mathrm{~nm}$, respectively. A similar procedure was followed for experiments \#7-9, 19-21 and 25-27, which were conducted at $700 \mathrm{~K}$ and 10 Torr.

The insets of Fig. 19 compare the $700 \mathrm{~K}$ backgroundsubtracted and normalized absorbance measurements at the three probe wavelengths. All of the other absorbance traces are shown in Table S5 (ESI $\dagger$ ). As already discussed (Section 4.2) $505.3 \mathrm{~nm}$ absorbance of $\mathrm{C}_{6} \mathrm{H}_{5}$ typically returns to the baseline within $\pm 10 \%$ due to noise and imperfect background subtraction (Table 2). $\mathrm{C}_{6} \mathrm{H}_{5}$ continues to contribute substantially to the absorbance at the lower wavelengths as well, similar to previous measurements of its UV-visible spectrum. ${ }^{56}$ At $447.7 \mathrm{~nm}$, the absorbance also essentially returns to the baseline, but at $408.4 \mathrm{~nm}$ there is a clear, reproducible baseline-shift of $\sim 30 \%$, which exceeds the typical baseline shift fluctuations of $\pm 10 \%$. 

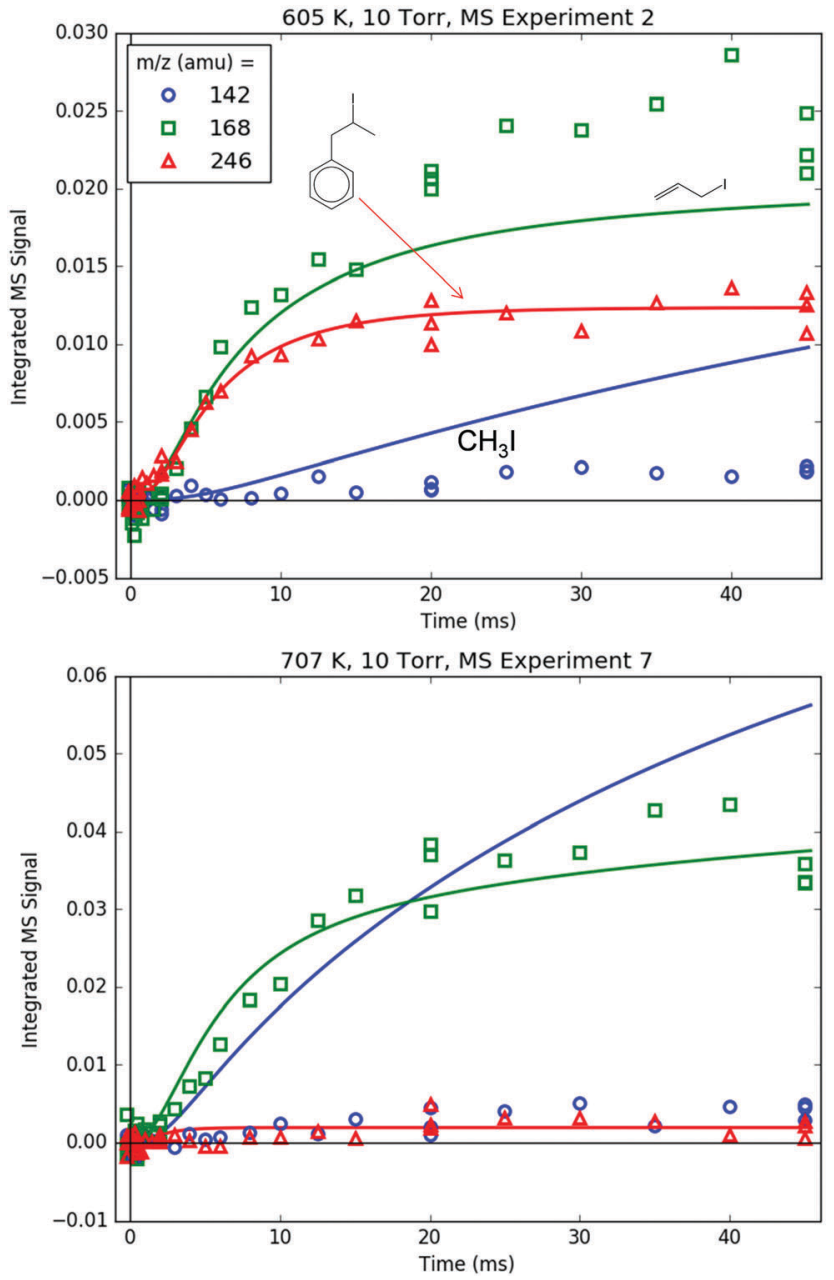

Fig. 18 Measured (markers) and modelled (thick lines) 142 (blue), 168 (green) and 246 (red) amu MBMS signals under indicated conditions. All signals are exclusively attributed to the parent cation of an alkyl iodide: methyl, allyl and i1 iodide, respectively.

Similar results were obtained at $600 \mathrm{~K}$ (no reliable baseline shift at 505.3 and $447.7 \mathrm{~nm}$, and a possible baseline shift of $\sim 10 \%$ at $408.4 \mathrm{~nm}$ ). Once again, the model of Section 4.4 was used to gain quantitative insight into what is happening.

The normalized absorbance traces at 408.4 and $447.7 \mathrm{~nm}$ were modelled as weighted sums of the simulated $\mathrm{C}_{6} \mathrm{H}_{5}$ and product concentration profiles in the reactor (unsampled):

$$
A / A_{0}=C_{\mathrm{C}_{6} \mathrm{H}_{5}} / C_{\mathrm{C}_{6} \mathrm{H}_{5,0}}+\alpha C_{\text {product }} / C_{\mathrm{C}_{6} \mathrm{H}_{5,0}}
$$

where product is either $\mathrm{C}_{3} \mathrm{H}_{5}$ or $\mathbf{p 1 0}, C_{\mathrm{C}_{6} \mathrm{H}_{5,0}}$ is the initial $\mathrm{C}_{6} \mathrm{H}_{5}$ concentration and $\alpha$ is the weighting factor that accounts for the ratio of product to $\mathrm{C}_{6} \mathrm{H}_{5}$ cross sections at the given visible wavelength. $\alpha$ was measured as $\sim 1$ for $\mathrm{C}_{3} \mathrm{H}_{5}$ at $408.4 \mathrm{~nm}$ (at both 600 and $700 \mathrm{~K}$ ) by back-to-back flash-photolysis experiments with $\mathrm{C}_{6} \mathrm{H}_{5} \mathrm{I}$ and $\mathrm{C}_{3} \mathrm{H}_{5} \mathrm{I}$. For $\mathbf{p 1 0}$ at $447.7 \mathrm{~nm}, \alpha$ was approximated as 1 at both 600 and $700 \mathrm{~K}$ based on the measured cross section of $\mathrm{C}_{6} \mathrm{H}_{5}$ in this work $\left(\sim 2 \times 10^{-19} \mathrm{~cm}^{2}\right.$, largely independent of either $T$ or wavelength) and the experiments of Matsugi et al. measuring the $T$-dependence of $\mathbf{p 1 0}$ 's cross section. ${ }^{55}$
The model results are shown as thick red lines in the insets of Fig. 19, where the individual contributions of $C_{\mathrm{C}_{6} \mathrm{H}_{5}}$ and $C_{\text {product }}$ are also shown as dashed lines. Although the model is in good quantitative agreement with the 447.7 and $505.3 \mathrm{~nm}$ measurements, at $408.4 \mathrm{~nm}$ the baseline shift in the model is only $\sim 10 \%$ compared to $\sim 30 \%$ measured experimentally. However, it was found that the predicted $\mathrm{C}_{3} \mathrm{H}_{5}$ yield (and the modelled baseline shift at $408.4 \mathrm{~nm}$ ) was sensitive to the $\mathrm{C}_{3} \mathrm{H}_{5}+$ $\mathrm{I} \rightarrow \mathrm{C}_{3} \mathrm{H}_{5} \mathrm{I}$ rate coefficient. If this reaction was entirely removed, the $\mathrm{C}_{3} \mathrm{H}_{5}$ yield approximately doubled at short times, and the modelled $408.4 \mathrm{~nm}$ baseline shift increased to around $20 \%$ (Fig. S37, ESI $\dagger$ ), which is in reasonable agreement with the $30 \%$ measured experimentally considering the $10 \%$ baseline fluctuations regularly observed. Of course, $\mathrm{C}_{3} \mathrm{H}_{5}+\mathrm{I}$ recombination is occurring, because $\mathrm{C}_{3} \mathrm{H}_{5} \mathrm{I}$ was observed as an MBMS product. Perhaps $\mathrm{C}_{3} \mathrm{H}_{5}$ and $\mathrm{I}$ are recombining on the walls close to where MBMS sampling occurs, whereas in the gas-phase where $\mathrm{C}_{3} \mathrm{H}_{5}$ is probed by absorbance, little recombination occurs due to the pressure dependence of the reaction (which is not included in the model).

A different explanation for the poorly modelled $408.4 \mathrm{~nm}$ baseline shift is absorbance by something else entirely, especially given the relatively short wavelength. In any case, MBMS detection of stable products $\left(\mathrm{C}_{6} \mathrm{H}_{6}\right.$ in the case of $\mathrm{C}_{6} \mathrm{H}_{5}+\mathrm{C}_{3} \mathrm{H}_{6} \mathrm{H}$-abstraction) is a much preferred method for quantifying product branching over trying to probe for one radical product with laser absorbance in a "soup" of different radicals that might also absorb. It was demonstrated in the previous section that the model developed in this work could quantitatively explain all of the major product MBMS signals, including $\mathrm{C}_{6} \mathrm{H}_{6}$. The inability of the same model to quantitatively match all of the absorbance experiments should not detract from it significantly, especially considering the complications involved in quantitative absorbance measurements mentioned above.

\subsection{Generalizing aromatic-catalyzed 1,2-hydrogen-migration to other alkylaromatic systems using RMG}

The aromatic-catalyzed 1,2-H-migration proposed in Section 4.1 and experimentally supported in Section 4.4 is not limited to the $\mathrm{C}_{6} \mathrm{H}_{5}+\mathrm{C}_{3} \mathrm{H}_{6}$ system but will apply to any arbitrary alkylaromatic radical system with at least three carbons in a linear chain and at least one $\mathrm{H}$ in an ortho-position. RMG, and other automatic mechanism generators like it, provides a convenient tool for generalizing new chemistry findings, such as the aromatic-catalyzed 1,2-H-migration, and exploring their implications for more complicated systems. In this case, the slightly more complicated alkylaromatic system considered is 1-naphthyl radical +2 -butene, $1-\mathrm{C}_{10} \mathrm{H}_{7}+2-\mathrm{C}_{4} \mathrm{H}_{8}$, the radical addition product for which is shown and labelled in Scheme 4. This particular system was chosen because both the number of aromatic rings and the length of the side chain have increased by one compared to $\mathrm{C}_{6} \mathrm{H}_{5}+\mathrm{C}_{3} \mathrm{H}_{6}$. As will be shown, even these modest modifications to the original $\mathrm{C}_{6} \mathrm{H}_{5}+\mathrm{C}_{3} \mathrm{H}_{6}$ framework will have consequential effects on the possible chemistry.

As already discussed in Section 3 and Section S1.1 (ESI $\dagger$ ), RMG was "taught" the aromatic-catalyzed 1,2-H-migration 


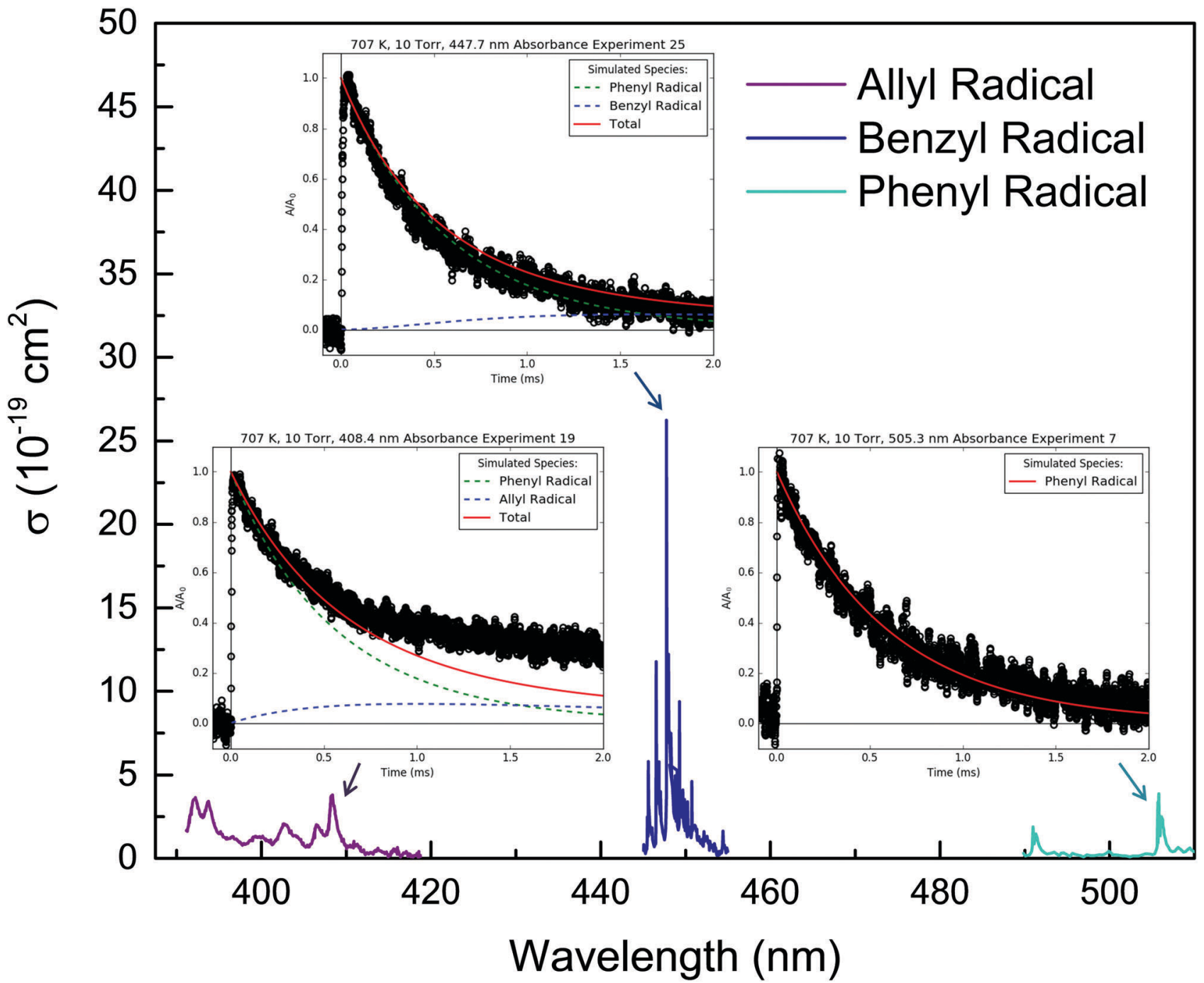

Fig. 19 Room temperature visible absorbance spectra measured by Tonokura et al. for allyl, ${ }^{37}$ benzyl ${ }^{38}$ and phenyl ${ }^{14}$ radicals. The insets show representative absorbance traces (markers are measured and lines are modelled) measured in this work at the different wavelengths indicated and otherwise identical conditions $\left(707 \mathrm{~K}, 10 \mathrm{Torr},\left[\mathrm{C}_{3} \mathrm{H}_{6}\right]=7.5 \times 10^{15} \mathrm{~cm}^{-3}\right)$.

(and alkylaromatic chemistry more generally) using training reactions. Scheme 3 shows the "aromatic-catalyzed pathways" found by RMG and included in the final, converged mechanism for $1-\mathrm{C}_{10} \mathrm{H}_{7}+2-\mathrm{C}_{4} \mathrm{H}_{8}$ at $600 \mathrm{~K}$ and 1 atm. Following aromaticcatalyzed 1,2-H-migration, the radical formed was actually predicted to react in two main ways: $\beta$-scission of $\mathrm{C}_{2} \mathrm{H}_{4}$ to form an RSR directly (analogous to p10 $+\mathrm{C}_{2} \mathrm{H}_{4}$ formation in $\mathrm{C}_{6} \mathrm{H}_{5}+$ $\mathrm{C}_{3} \mathrm{H}_{6}$, right branch of Scheme 3) or a 1,3-phenyl shift and then $\beta$-scission of $\mathrm{C}_{3} \mathrm{H}_{6}$ to form another RSR (left branch). Both RSRs are then predicted to recombine with $\mathrm{CH}_{3}$ at various sites, although the extent of these reactions is overestimated by RMG as they were for $\mathrm{CH}_{3}+\mathbf{p 1 0}$ recombination (Scheme S1, ESI $\dagger$ ).

From Scheme 3 alone it can already be seen that simply adding one more carbon to the alkyl chain of i1 opens up new chemistry (left branch). However, there are two more novel applications of the "aromatic-catalyzed" concept to the $1-\mathrm{C}_{10} \mathrm{H}_{7}+$ $2-\mathrm{C}_{4} \mathrm{H}_{8}$ system that were not found by RMG. In the first, rather than the ortho-carbon (labelled 2 in Scheme 4) serving as the "active site" in the aromatic catalyst (source and sink of $\mathrm{H}$ ), carbon 9 could instead function as the active site. In fact, carbon 9 is probably a better active site than carbon 2 because in the rate-limiting step of the aromatic-catalyzed 1,2-H-migration carbon 2 loses its $\mathrm{H}$ in a 5-membered-ring TS (Fig. 1 and 3) whereas carbon 9 would form a more favourable 6-membered-ring TS. In the second application, carbon 2 could still be the active site, but instead of abstracting an $\mathrm{H}$ back from carbon 11 in the second step, as in Scheme 3, it could abstract an $\mathrm{H}$ from carbon 14. In this case, the net effect would be a 1,3-H-migration. The fact that RMG was unable to extrapolate the aromatic-catalyzed 1,2-H-migration, on which it was trained, to a different active site or to a $1,3-\mathrm{H}$ migration (or to a combination of both: a 1-3-H-migration using carbon 9 as the active site) points to areas of future work.

Fig. 20 shows RMG's quantitative predictions of the product branching for $1-\mathrm{C}_{10} \mathrm{H}_{7}+2-\mathrm{C}_{4} \mathrm{H}_{8}$ at $600 \mathrm{~K}$ and $1 \mathrm{~atm}$. Just as in the case of $\mathrm{C}_{6} \mathrm{H}_{5}+\mathrm{C}_{3} \mathrm{H}_{6}$, the major products are from $\mathrm{H}$-abstraction (red line) and radical addition followed by $\mathrm{CH}_{3}$ 


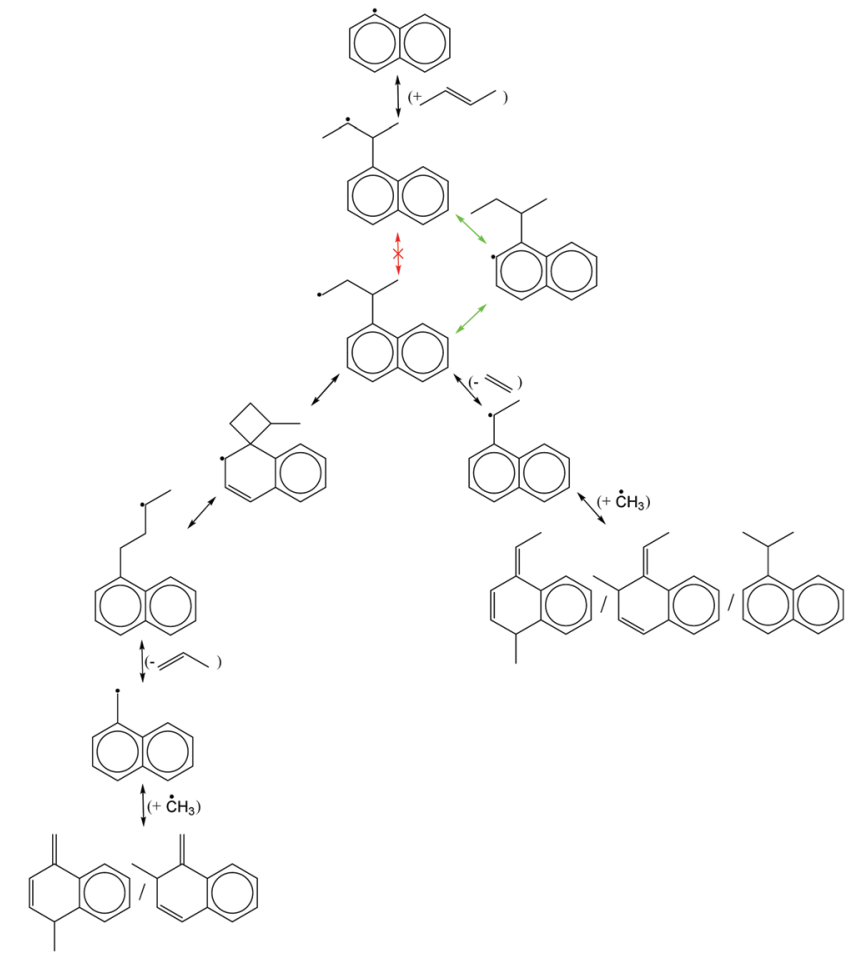

Scheme 3 Aromatic-catalyzed 1,2-hydrogen-migration (green arrows) for 1-naphthyl radical +2 -butene and subsequent RMG-predicted pathways.

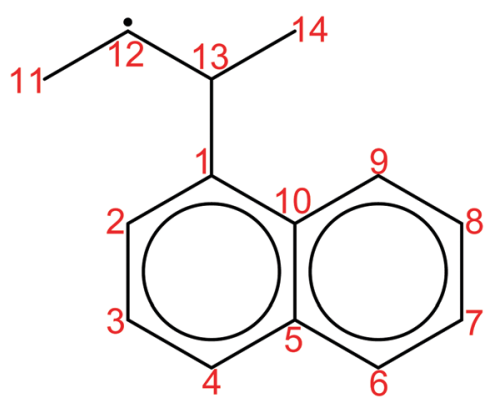

Scheme 4 Addition product of 1-naphthyl radical + 2-butene with atom labels.

loss (black) or H loss (magenta and green). All of the "aromaticcatalyzed products" each have a yield of less than $1 \%$, and in total they only account for $\sim 4 \%$ of the product branching. However, if RMG had found the other three aromatic-catalyzed reactions described in the previous paragraph the branching would be higher. Nonetheless, the general applicability of aromatic-catalyzed reactions has been demonstrated and applied to the example 1- $\mathrm{C}_{10} \mathrm{H}_{7}+2-\mathrm{C}_{4} \mathrm{H}_{8}$ system using RMG. Given the staggering number of different alkylaromatic structures that would be encountered in a real application (e.g., gasoline, kerogen), a tool like RMG is needed to extrapolate findings made for model systems (e.g., aromatic-catalyzed 1,2-H-migration in $\mathrm{C}_{6} \mathrm{H}_{5}+\mathrm{C}_{3} \mathrm{H}_{6}$ ) to all possible analogous systems, even if the extrapolation is currently unsophisticated.
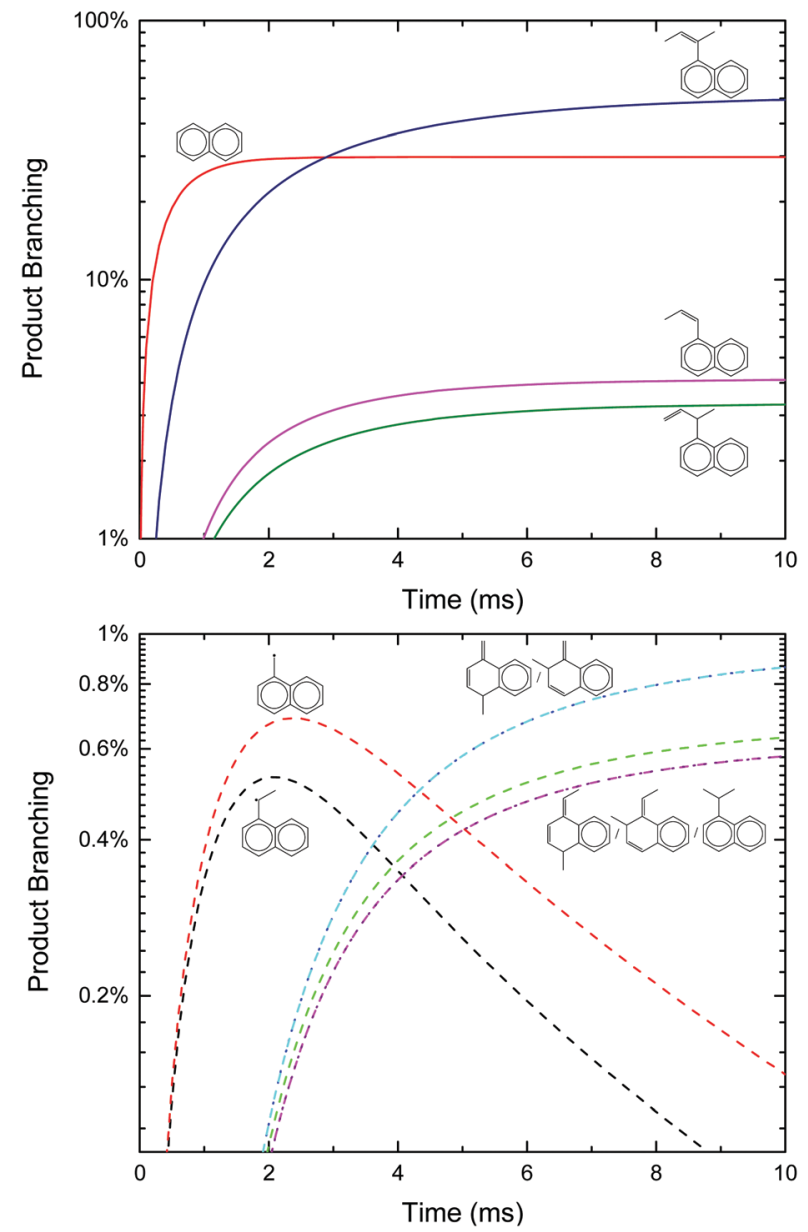

Fig. 20 Major (top) and aromatic-catalyzed (bottom) products of 1-naphthyl radical + 2-butene predicted by RMG.

\section{Conclusions}

By applying a different experimental approach (flash photolysis with time-resolved MBMS) to a chemical system that has already been studied extensively both experimentally and computationally $\left(\mathrm{C}_{6} \mathrm{H}_{5}+\mathrm{C}_{3} \mathrm{H}_{6}\right)$, several new insights were made.

First, and most importantly, a previously unreported aromatic-catalyzed 1,2-H-migration was proposed to explain unexpected benzyl radical formation observed experimentally from $\mathrm{C}_{6} \mathrm{H}_{5}+\mathrm{C}_{3} \mathrm{H}_{6}$. Quantum calculations of the energetics and RRKM/ME calculations of the kinetics for the new pathway were both favourable, predicting up to $\sim 10 \%$ and $\sim 15 \%$ product branching to the benzyl radical under thermal and single collision conditions, respectively. In order to gain further confidence in these predictions, a detailed model for the flash photolysis/MBMS experiment was developed that includes both hydrocarbon and iodine chemistry, as well a simple empirical model for transport. The model could quantitatively explain the complicated time- and temperature-dependence of the unexpected product (as well as the other four primary product $m / z$ 's) observed experimentally, providing strong support for the aromaticcatalyzed pathway as the main route to the benzyl radical (and resonance stabilized radicals more generally). 
Second, the extent of $\mathrm{H}$-abstraction from $\mathrm{C}_{6} \mathrm{H}_{5}+\mathrm{C}_{3} \mathrm{H}_{6}$ was quantified experimentally for the first time, using MBMS detection of the stable product $\left(\mathrm{C}_{6} \mathrm{H}_{6}\right)$, and was found to be in good agreement with the model described above (and the theoretical calculations upon which the chemistry portion of the model relies). Attempts to quantify $\mathrm{H}$-abstraction by probing for the radical product $\left(\mathrm{C}_{3} \mathrm{H}_{5}\right)$ with laser absorbance were less quantitatively successful, however, either due to poorly understood secondary chemistry involving the I atom or due to spectral overlap of other radicals at the relatively short wavelength used (408.4 nm).

Finally, the competition between $\mathrm{CH}_{3}$-loss and $\mathrm{H}$-loss following radical addition of $\mathrm{C}_{6} \mathrm{H}_{5}+\mathrm{C}_{3} \mathrm{H}_{6}$ was quantified experimentally and matched by the model. Under the conditions of these experiments (600 and $700 \mathrm{~K}$ ) $\mathrm{CH}_{3}$-loss was dominant.

The only outstanding discrepancy in the $\mathrm{C}_{6} \mathrm{H}_{5}+\mathrm{C}_{3} \mathrm{H}_{6}$ literature that this work did not address experimentally was the isomeric identity of the H-loss product. However, trapping of the effluent of the flash photolysis reactor followed by GC/MS detection of the stable $\mathrm{C}_{6} \mathrm{H}_{5}+\mathrm{C}_{3} \mathrm{H}_{6}$ products might be a practical approach to addressing this issue in the future.

Given that the current theoretical understanding of $\mathrm{C}_{6} \mathrm{H}_{5}+$ $\mathrm{C}_{3} \mathrm{H}_{6}$ was sufficient to quantitatively explain the many experimental results of this work, this knowledge was "taught" to RMG using the language of training reactions. The ability of RMG to apply this knowledge to a slightly more complicated alkylaromatic system, $1-\mathrm{C}_{10} \mathrm{H}_{7}+2-\mathrm{C}_{4} \mathrm{H}_{8}$, was demonstrated, although areas for improvement were clearly identified. Specifically, RMG only applied the aromatic-catalyzed concept narrowly to the kind of $1,2-\mathrm{H}$ migration seen in the $\mathrm{C}_{6} \mathrm{H}_{5}+\mathrm{C}_{3} \mathrm{H}_{6}$ system, instead of applying it more broadly to 1,3-H-migrations with different "active-sites" of the aromatic catalyst. Despite these shortcomings, RMG and similar automated tools are currently the best options for extrapolating detailed chemistry insights, such as the ones made in this work, to real applications. Hopefully the overall framework presented here for translating fundamental experimental and theoretical insights into broader applications using RMG will serve as a guide for future fruitful work. For example, experiments with naphthyl radicals or butene isomers would be a logical extension of this work.

\section{Conflicts of interest}

There are no conflicts to declare.

\section{Acknowledgements}

This research was supported by SABIC and used resources of the National Energy Research Scientific Computing Center, a DOE Office of Science User Facility supported by the Office of Science of the U.S. Department of Energy under Contract No. DE-AC02-05CH11231. T.-C. C. received funding from Think Global Education Trust. Professor Guozhu Liu provided the inspiration for this work and Mengjie (Max) Liu both laid the necessary groundwork for aromatic chemistry in RMG and provided critical support.

\section{Notes and references}

1 A. M. Mebel, Y. Georgievskii, A. W. Jasper and S. J. Klippenstein, Faraday Discuss., 2016, 195, 637-670.

2 W. Yuan, Y. Li, P. Dagaut, Y. Wang, Z. Wang and F. Qi, Combust. Flame, 2017, 186, 178-192.

3 J. Hansen and L. Nazarenko, Proc. Natl. Acad. Sci. U. S. A., 2004, 101, 423-428.

4 D. W. Dockery, C. A. Pope, X. Xu, J. D. Spengler, J. H. Ware, M. E. Fay, B. G. Ferris and F. E. Speizer, N. Engl. J. Med., 1993, 329, 1753-1759.

5 C. Xu, A. S. Al Shoaibi, C. Wang, H.-H. Carstensen and A. M. Dean, J. Phys. Chem. A, 2011, 115, 10470-10490.

6 H. J. Hefter, T. A. Hecht and G. S. Hammond, J. Am. Chem. Soc., 1972, 94, 2793-2797.

7 J. Park, G. J. Nam, I. V. Tokmakov and M. C. Lin, J. Phys. Chem. A, 2006, 110, 8729-8735.

8 F. Zhang, X. Gu, Y. Guo and R. I. Kaiser, J. Phys. Chem. A, 2008, 112, 3284-3290.

9 R. I. Kaiser, D. S. N. Parker, M. Goswami, F. Zhang, V. V. Kislov, A. M. Mebel, J. Aguilera-Iparraguirre and W. H. Green, Phys. Chem. Chem. Phys., 2012, 14, 720-729.

10 F. Zhang, R. I. Kaiser, A. Golan, M. Ahmed and N. Hansen, J. Phys. Chem. A, 2012, 116, 3541-3546.

11 V. V. Kislov, A. M. Mebel, J. Aguilera-Iparraguirre and W. H. Green, J. Phys. Chem. A, 2012, 116, 4176-4191.

12 D. R. Albert, M. A. Todt and H. F. Davis, J. Phys. Chem. A, 2013, 117, 13967-13975.

13 Z. Wang, L. Zhang and F. Zhang, J. Phys. Chem. A, 2014, 118, 6741-6748.

14 K. Tonokura, Y. Norikane, M. Koshi, Y. Nakano, S. Nakamichi, M. Goto, S. Hashimoto, M. Kawasaki, M. P. Sulbaek Andersen, M. D. Hurley and T. J. Wallington, J. Phys. Chem. A, 2002, 106, 5908-5917.

15 J. E. Middaugh, PhD thesis, Massachusetts Institute of Technology, 2014.

16 Z. J. Buras, E. E. Dames, S. S. Merchant, G. Liu, R. M. I. Elsamra and W. H. Green, J. Phys. Chem. A, 2015, 119, 7325-7338.

17 J. E. Middaugh, Z. J. Buras, M. Matrat, T.-C. Chu, Y.-S. Kim, I. M. Alecu, A. K. Vasiliou, C. F. Goldsmith and W. H. Green Jr, Rev. Sci. Instrum., under review.

18 J. R. Wyatt, J. J. Decorpo, M. V. McDowell and F. E. Saalfeld, Int. J. Mass Spectrom. Ion Phys., 1975, 16, 33-38.

19 K. Tonokura, N. Kanno, Y. Yamamoto and H. Yamada, Int. J. Mass Spectrom., 2010, 290, 9-13.

20 H. Ismail, C. F. Goldsmith, P. R. Abel, P.-T. Howe, A. Fahr, J. B. Halpern, L. E. Jusinski, Y. Georgievskii, C. A. Taatjes and W. H. Green, J. Phys. Chem. A, 2007, 111, 6843-6851.

21 Z. J. Buras, R. M. I. Elsamra, A. Jalan, J. E. Middaugh and W. H. Green, J. Phys. Chem. A, 2014, 118, 1997-2006.

22 L. N. Krasnoperov, J. T. Niiranen, D. Gutman, C. F. Melius and M. D. Allendorf, J. Phys. Chem., 1995, 99, 14347-14358.

23 A. G. Sage, T. A. A. Oliver, D. Murdock, M. B. Crow, G. A. D. Ritchie, J. N. Harvey and M. N. R. Ashfold, Phys. Chem. Chem. Phys., 2011, 13, 8075-8093. 
24 C.-M. Tseng, Y. M. Choi, C.-L. Huang, C.-K. Ni, Y. T. Lee and M. C. Lin, J. Phys. Chem. A, 2004, 108, 7928-7935.

25 T. Yu and M. C. Lin, J. Am. Chem. Soc., 1994, 116, 9571-9576.

26 S. S. Kumaran, M. C. Su and J. V. Michael, Chem. Phys. Lett., 1997, 269, 99-106.

27 NIST, Precomputed vibrational scaling factors, http:// cccbdb.nist.gov/vibscalejust.asp.

28 A. M. Mebel, A. Landera and R. I. Kaiser, J. Phys. Chem. A, 2017, 121, 901-926.

29 M. J. Frisch, G. W. Trucks, H. B. Schlegel, G. E. Scuseria, M. A. Robb, J. R. Cheeseman, J. A. Montgomery, T. Vreven, K. N. Kudin, J. C. Burant, J. M. Millam, S. S. Iyengar, J. Tomasi, V. Barone, B. Mennucci, M. Cossi, G. Scalmani, N. Rega, G. A. Petersson, H. Nakatsuji, M. Hada, M. Ehara, K. Toyota, R. Fukuda, J. Hasegawa, M. Ishida, T. Nakajima, Y. Honda, O. Kitao, H. Nakai, M. Klene, X. Li, J. E. Knox, H. P. Hratchian, J. B. Cross, V. Bakken, C. Adamo, J. Jaramillo, R. Gomperts, R. E. Stratmann, O. Yazyev, A. J. Austin, R. Cammi, C. Pomelli, J. W. Ochterski, P. Y. Ayala, K. Morokuma, G. A. Voth, P. Salvador, J. J. Dannenberg, V. G. Zakrzewski, S. Dapprich, A. D. Daniels, M. C. Strain, O. Farkas, D. K. Malick, A. D. Rabuck, K. Raghavachari, J. B. Foresman, J. V. Ortiz, Q. Cui, A. G. Baboul, S. Clifford, J. Cioslowski, B. B. Stefanov, G. Liu, A. Liashenko, P. Piskorz, I. Komaromi, R. L. Martin, D. J. Fox, T. Keith, A. Laham, C. Y. Peng, A. Nanayakkara, M. Challacombe, P. M. W. Gill, B. Johnson, W. Chen, M. W. Wong, C. Gonzalez and J. A. Pople, Gaussian 03, Revision D.01, 2003.

30 H.-J. Werner, P. J. Knowles, G. Knizia, F. R. Manby and M. Schütz, Wiley Interdiscip. Rev.: Comput. Mol. Sci., 2012, 2, 242-253.

31 C. W. Gao, J. W. Allen, W. H. Green and R. H. West, Comput. Phys. Commun., 2016, 203, 212-225.

32 C. Eckart, Phys. Rev., 1930, 35, 1303-1309.

33 J. W. Allen, C. F. Goldsmith and W. H. Green, Phys. Chem. Chem. Phys., 2012, 14, 1131-1155.

34 A. W. Jasper, C. M. Oana and J. A. Miller, Proc. Combust. Inst., 2015, 35, 197-204.

35 CHEMKIN software is distributed by ANSYS, 2013.

36 C. Yan, S. Kocevska and L. N. Krasnoperov, J. Phys. Chem. A, 2016, 120, 6111-6121.
37 K. Tonokura and M. Koshi, J. Phys. Chem. A, 2000, 104, 8456-8461.

38 K. Tonokura and M. Koshi, J. Phys. Chem. A, 2003, 107, 4457-4461.

39 C. L. Yaws, Yaws' Critical Property Data for Chemical Engineers and Chemists, http://app.knovel.com/hotlink/toc/id:kpYCPD CECD/yaws-critical-property/yaws-critical-property.

40 G. M. Bradley and H. L. Strauss, J. Phys. Chem., 1975, 79, 1953-1957.

41 H. Ismail, P. R. Abel, W. H. Green, A. Fahr, L. E. Jusinski, A. M. Knepp, J. Zádor, G. Meloni, T. M. Selby, D. L. Osborn and C. A. Taatjes, J. Phys. Chem. A, 2009, 113, 1278-1286.

42 Z. J. Buras, R. M. I. Elsamra and W. H. Green, J. Phys. Chem. Lett., 2014, 5, 2224-2228.

43 M. D. Morse, in Experimental Methods in the Physical Sciences, ed. F. B. Dunning and R. G. Hulet, Academic Press, 1996, vol. 29, pp. 21-47.

44 A. Comandini, T. Malewicki and K. Brezinsky, J. Phys. Chem. A, 2012, 116, 2409-2434.

45 R. S. Tranter, S. J. Klippenstein, L. B. Harding, B. R. Giri, X. Yang and J. H. Kiefer, J. Phys. Chem. A, 2010, 114, 8240-8261.

46 M. T. Baeza-Romero, M. A. Blitz, A. Goddard and P. W. Seakins, Int. J. Chem. Kinet., 2012, 44, 532-545.

47 S. J. Blanksby and G. B. Ellison, Acc. Chem. Res., 2003, 36, 255-263.

48 G. P. Kota, J. W. Coburn and D. B. Graves, J. Vac. Sci. Technol., A, 1999, 17, 282-290.

49 M. Bobeldijk, W. J. van der Zande and P. G. Kistemaker, Chem. Phys., 1994, 179, 125-130.

50 J. C. Traeger and B. M. Kompe, Int. J. Mass Spectrom. Ion Processes, 1990, 101, 111-120.

51 S. Mulenko, Rev. Roum. Phys., 1987, 32, 173.

52 J. Berkowitz, J. P. Greene, H. Cho and B. Ruscić, J. Chem. Phys., 1987, 86, 674-676.

53 B. A. Williams and T. A. Cool, J. Chem. Phys., 1991, 94, 6358-6366.

54 Y.-R. Luo and P. D. Pacey, Int. J. Mass Spectrom. Ion Processes, 1992, 112, 63-77.

55 A. Matsugi and A. Miyoshi, Chem. Phys. Lett., 2012, 521, 26-30.

56 T. J. Wallington, H. Egsgaard, O. J. Nielsen, J. Platz, J. Sehested and T. Stein, Chem. Phys. Lett., 1998, 290, 363-370. 